NCCN

\section{Multiple Myeloma, Version 2.2016}

\section{Clinical Practice Guidelines in Oncology}

Kenneth C. Anderson, MD; Melissa Alsina, MD; Djordje Atanackovic, MD; J. Sybil Biermann, MD; Jason C. Chandler, MD; Caitlin Costello, MD; Benjamin Djulbegovic, MD, PhD; Henry C. Fung, MD, FRCP; Cristina Gasparetto, MD; Kelly Godby, MD; Craig Hofmeister, MD, MPH; Leona Holmberg, MD, PhD; Sarah Holstein, MD, PhD; Carol Ann Huff, MD; Adetola Kassim, MD, MS; Amrita Y. Krishnan, MD; Shaji K. Kumar, MD; Michaela Liedtke, MD; Matthew Lunning, DO; Noopur Raje, MD;
Seema Singhal, MD; Clayton Smith, MD; George Somlo, MD; Keith Stockerl-Goldstein, MD; Steven P. Treon, MD, PhD; Donna Weber, MD; Joachim Yahalom, MD; Dorothy A. Shead, MS; and Rashmi Kumar, PhD

\section{Overview}

The American Cancer Society has estimated 26,850 new multiple myeloma (MM) cancer cases in the United States in 2015, with an estimated 11,240 deaths. ${ }^{1}$ The mean age of affected individuals is 62 years for men $(75 \%>70$ years of age $)$ and 61 years for women $(79 \%>70$ years of age). The 5 -year survival rate reported in the SEER database has increased from $25 \%$ in 1975 to $34 \%$ in 2003 due to newer and more effective treatment options available.

\begin{abstract}
Multiple myeloma (MM) is a malignant neoplasm of plasma cells that accumulate in bone marrow, leading to bone destruction and marrow failure. Recent statistics from the American Cancer Society indicate that the incidence of MM is increasing. The NCCN Clinical Practice Guidelines in Oncology (NCCN Guidelines) included in this issue address management of patients with solitary plasmacytoma and newly diagnosed MM. (J Natl Compr Canc Netw 2015;13:1398-1435)
\end{abstract}

\section{NCCN Categories of Evidence and Consensus}

Category 1: Based upon high-level evidence, there is uniform NCCN consensus that the intervention is appropriate.

Category 2A: Based upon lower-level evidence, there is uniform NCCN consensus that the intervention is appropriate.

Category 2B: Based upon lower-level evidence, there is NCCN consensus that the intervention is appropriate.

Category 3: Based upon any level of evidence, there is major NCCN disagreement that the intervention is appropriate.

All recommendations are category $2 \mathrm{~A}$ unless otherwise noted.

Clinical trials: NCCN believes that the best management for any cancer patient is in a clinical trial. Participation in clinical trials is especially encouraged.

\section{Please Note}

The NCCN Clinical Practice Guidelines in Oncology (NCCN Guidelines ${ }^{\circledR}$ ) are a statement of consensus of the authors regarding their views of currently accepted approaches to treatment. Any clinician seeking to apply or consult the NCCN Guidelines ${ }^{\circledR}$ is expected to use independent medical judgment in the context of individual clinical circumstances to determine any patient's care or treatment. The National Comprehensive Cancer Network $^{\circledR}\left(\mathrm{NCCN}^{\circledR}\right)$ makes no representation or warranties of any kind regarding their content, use, or application and disclaims any responsibility for their applications or use in any way. The full NCCN Guidelines for Multiple Myeloma are not printed in this issue of JNCCN but can be accessed online at NCCN.org.

(c) National Comprehensive Cancer Network, Inc. 2015, All rights reserved. The NCCN Guidelines and the illustrations herein may not be reproduced in any form without the express written permission of NCCN.

\section{Disclosures for the NCCN Multiple Myeloma Panel}

At the beginning of each NCCN Guidelines panel meeting, panel members review all potential conflicts of interest. NCCN, in keeping with its commitment to public transparency, publishes these disclosures for panel members, staff, and NCCN itself.

Individual disclosures for the NCCN Multiple Myeloma Panel members can be found on page 1435 . (The most recent version of these guidelines and accompanying disclosures are available on the NCCN Web site at NCCN.org.)

These guidelines are also available on the Internet. For the latest update, visit NCCN.org. 
MM is typically sensitive to a variety of cytotoxic drugs, both as initial treatment and as treatment for relapsed disease. Unfortunately, responses are transient, and MM is not considered curable with current approaches. However, treatment of MM has been rapidly evolving because of the introduction of new drugs, such as thalidomide, lenalidomide, and bortezomib. ${ }^{2-4}$ In addition, there is emerging understanding of the microenvironment of the bone marrow, creating the rationale for new combinations of therapies and new drug development. ${ }^{5,6}$ Studies of the associated cytogenetic abnormalities indicate that $\mathrm{MM}$ is a heterogeneous disease, suggesting that risk adapted approaches and individualizing treatment will further help refine patient management.

\section{Initial Diagnostic Workup}

The initial diagnostic workup in all patients should include a history and physical examination and the following baseline blood studies and biologic assessments to differentiate symptomatic and asymptomatic MM: a complete blood count (CBC) with differential and platelet counts; blood urea nitrogen (BUN); serum creatinine and serum electrolytes; serum calcium; albumin; lactate dehydrogenase (LDH); and beta2 microglobulin. Increased BUN and creatinine indicate decreased kidney function, whereas LDH levels help assess tumor cell burden. The level of beta2 microglobulin reflects the tumor mass and is now considered a standard measure of the tumor burden.

The monoclonal protein (M-protein) component in serum and urine is detected and evaluated by

Text cont. on page 1409 .

\section{NCCN Multiple Myeloma Oncology Panel Members}

*Kenneth C. Anderson, MD/Chair

Dana-Farber/Brigham and Women's Cancer Center

Melissa Alsina, MD¥

Moffitt Cancer Center

Djordje Atanackovic, MD

Huntsman Cancer Institute at the University of Utah

J. Sybil Biermann, MDף

University of Michigan Comprehensive Cancer Center

Jason C. Chandler, MDt

St. Jude Children's Research Hospital/

The University of Tennessee Health Science Center

Caitlin Costello, MD $¥ \xi \xi$

UC San Diego Moores Cancer Center

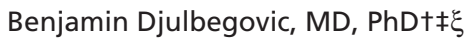

Moffitt Cancer Center

Henry C. Fung, MD, FRCP

Fox Chase Cancer Center

Cristina Gasparetto, MD

Duke Cancer Institute

Kelly Godby, MD†

University of Alabama at Birmingham

Comprehensive Cancer Center

Craig Hofmeister, MD, MPH

The Ohio State University Comprehensive Cancer Center James Cancer Hospital and Solove Research Institute

Leona Holmberg, $\mathrm{MD}, \mathrm{PhD} \xi$

Fred Hutchinson Cancer Research Center/

Seattle Cancer Care Alliance

Sarah Holstein, MD, PhD†‡

Roswell Park Cancer Institute

Carol Ann Huff, MD†

The Sidney Kimmel Comprehensive Cancer Center at Johns Hopkins
Adetola Kassim, MD, MS $\ddagger \xi$

Vanderbilt-Ingram Cancer Center

Amrita Y. Krishnan, MD‡

City of Hope Comprehensive Cancer Center

Shaji K. Kumar, MD $\neq \xi$

Mayo Clinic Cancer Center

Michaela Liedtke, MD‡

Stanford Cancer Institute

Matthew Lunning, DO†

Fred \& Pamela Buffet Cancer Center at

The Nebraska Medical Center

Noopur Raje, MD†‡

Massachusetts General Hospital Cancer Center

Seema Singhal, MD‡

Robert H. Lurie Comprehensive Cancer Center of

Northwestern University

Clayton Smith, MD $\xi$

University of Colorado Cancer Center

George Somlo, MD†‡P

City of Hope Comprehensive Cancer Center

Keith Stockerl-Goldstein, $\mathrm{MD}+\xi$

Siteman Cancer Center at Barnes-Jewish Hospital and

Washington University School of Medicine

Steven P. Treon, MD, PhD $†$

Dana-Farber/Brigham and Women's Cancer Center

Donna Weber, MD†

The University of Texas MD Anderson Cancer Center

Joachim Yahalom, MD§

Memorial Sloan Kettering Cancer Center

NCCN Staff: Dorothy A. Shead, MS, and Rashmi Kumar, PhD

KEY:

*Writing Committee Member

Specialties: †Medical Oncology; ‡Hematology; $\xi$ Bone Marrow

Transplantation; ๆSurgery/Surgical Oncology; §Radiotherapy/

Radiation Oncology; PInternal Medicine 
$\cdot H \& P$

- $\mathrm{CBC}$, differential, platelet count

- BUN/creatinine, electrolytes

- LDH

- Calcium/albumin

- Beta-2 microglobulin

- Serum free light chain (FLC) assay

- Serum quantitative immunoglobulins, serum protein electrophoresis (SPEP), serum immunofixation electrophoresis (SIFE)

- $24 \mathrm{~h}$ urine for total protein, urine protein electrophoresis (UPEP), urine

immunofixation electrophoresis (UIFE)

- Skeletal survey

- Unilateral bone marrow aspirate

+ biopsy, including bone marrow immunohistochemistry and/or bone marrow flow cytometry

- Cytogenetics

- FISH [del 13, del 17p13, t(4;14),

$\mathrm{t}(11 ; 14), \mathrm{t}(14 ; 16), 1 \mathrm{q} 21$ amplification]
Useful Under Some Circumstances - Imaging with whole body MRI or PET/CT scan ${ }^{a}$

- Tissue biopsy to diagnose a solitary osseous or extraosseous plasmacytoma

- Bone densitometry

- Plasma cell labeling index

- Staining of marrow and fat pad for amyloid

- Serum viscosity

- HLA typing

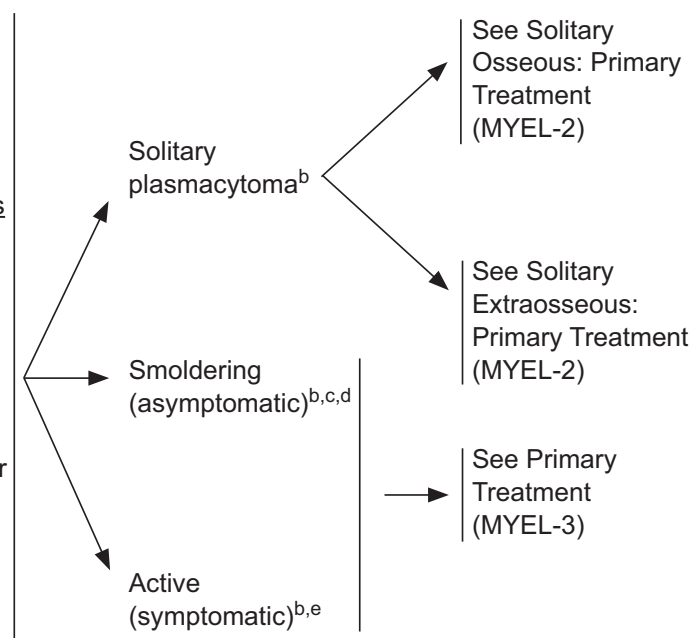

aAdditional testing (whole body MRI or PET/CT scan) recommended to discern active from smoldering myeloma, if skeletal survey is negative.

bSee Staging Systems for Multiple Myeloma (MYEL-A; available online, in these guidelines, at NCCN.org).

'See Smoldering (Asymptomatic) Myeloma (MYEL-B).

dIncludes Durie-Salmon Stage I Myeloma.

eSee Active (Symptomatic) Myeloma (MYEL-B).

MYEL-1

Clinical trials: NCCN believes that the best management of any cancer patient is in a clinical trial. Participation in clinical trials is especially encouraged. All recommendations are category $2 \mathrm{~A}$ unless otherwise indicated.

(C) JNCCN_Journal of the National Comprehensive Cancer Network | Volume 13 Number 11 | November 2015 
Multiple Myeloma, Version 2.2016

$\begin{array}{lll}\text { CLINICAL } & \text { PRIMARY } & \text { FOLLOW-UP/SURVEILLANCE } \\ \text { PRESENTATION } & \text { TREATMENT } & \end{array}$

PRESENTATION TREATMENT

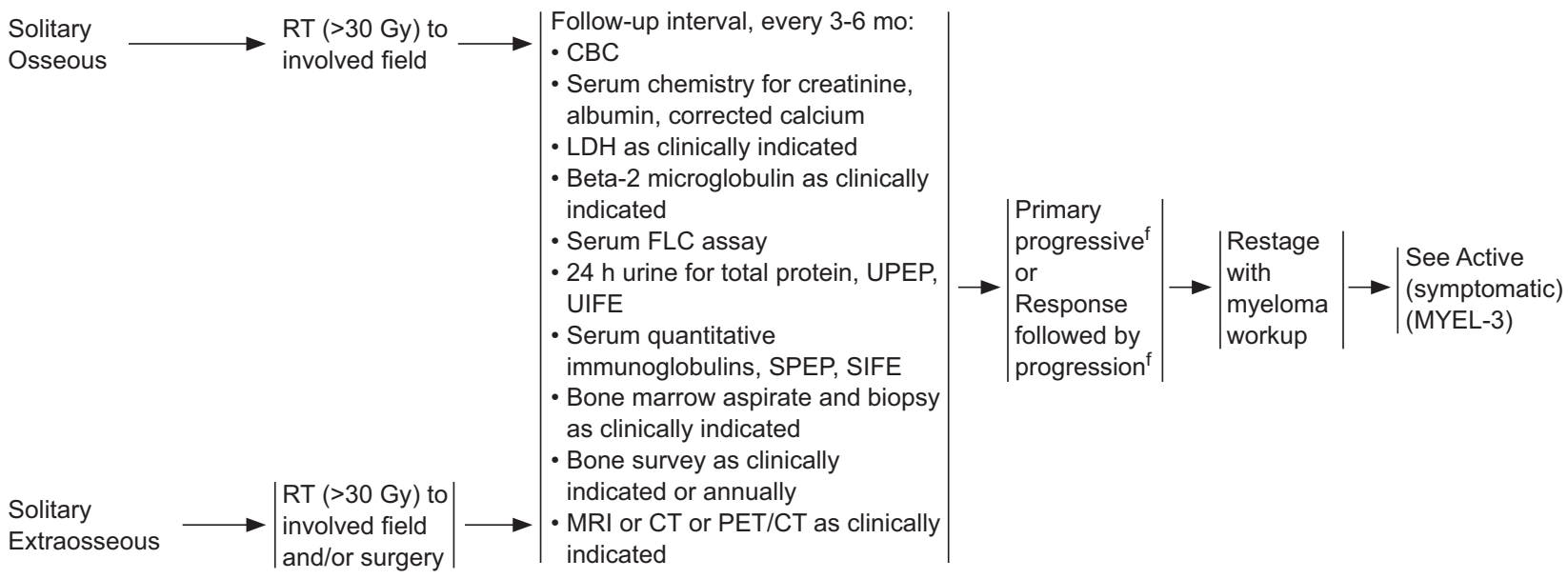

fSee Response Criteria for Multiple Myeloma (MYEL-C).

MYEL-2

Version 2.2016, 09-22-15 @2015 National Comprehensive Cancer Network, Inc. All rights reserved. The NCCN Guidelines ${ }^{\circledR}$ and this illustration may not be reproduced in any form without the express written permission of $\mathrm{NCCN}^{\circledR}$. 

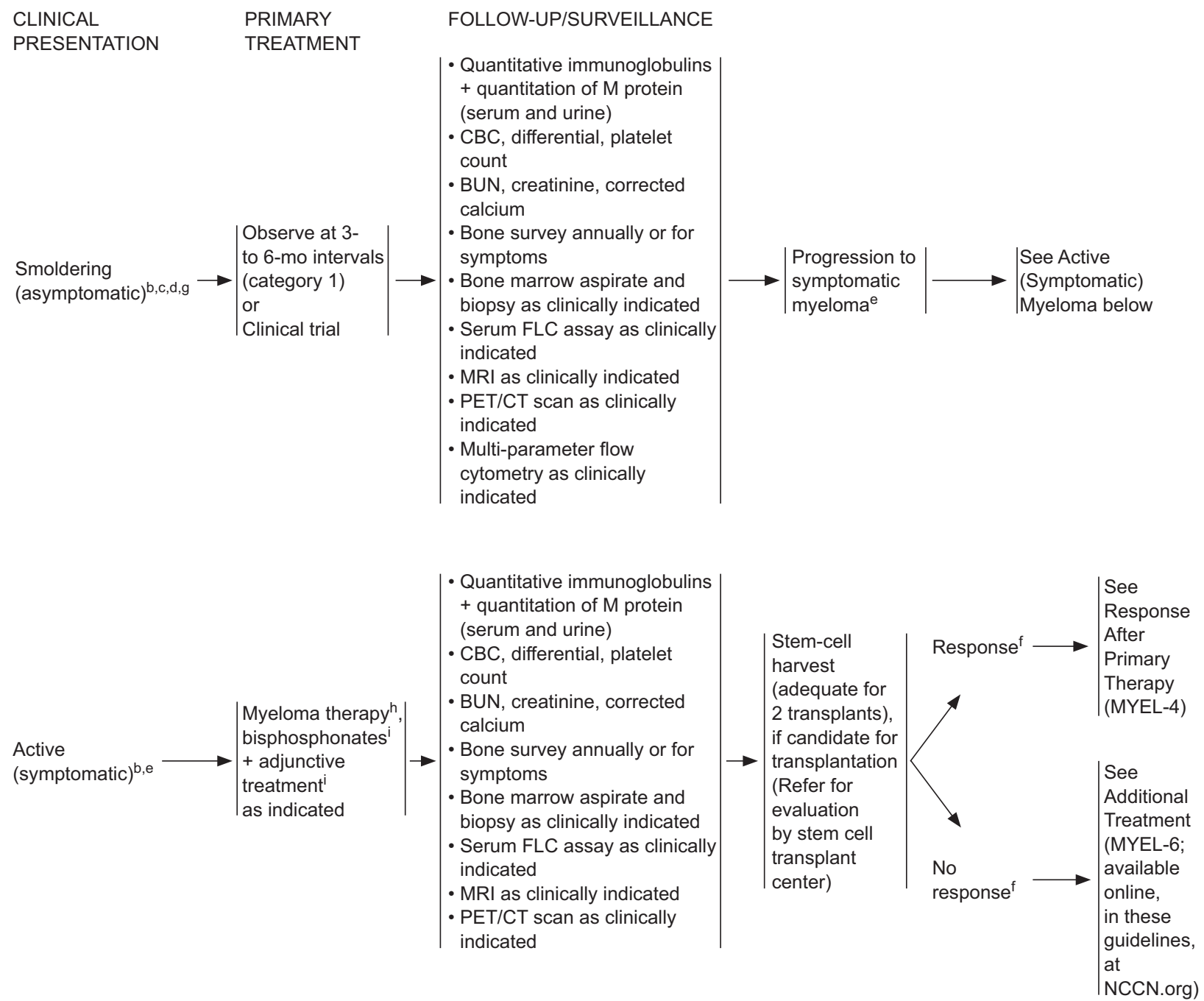

\footnotetext{
bSee Staging Systems for Multiple Myeloma (MYEL-A; available online, in these guidelines, at NCCN.org).

cSee Smoldering (Asymptomatic) Myeloma (MYEL-B)

dIncludes Durie-Salmon Stage I Myeloma.

eSee Active (Symptomatic) Myeloma (MYEL-B).

fSee Response Criteria for Multiple Myeloma (MYEL-C).

gA relatively small randomized prospective study has shown benefit of early treatment with lenalidomide and dexamethasone for a subset of patients with smoldering myeloma with certain high-risk features predictive for early clinical progression (Mateos MV, Hernandez M, Giraldo P, et al. Lenalidomide plus dexamethasone for high-risk smoldering multiple myeloma. N Engl J Med 2013;369:438-447). However, the high-risk criteria specified in the study are not in common use. Alternative criteria are under investigation (Dispienzeri A, Kyle R, Katzmann J, et al. Immunoglobulin free light chain ratio is an independent risk factor for progression of smoldering (asymptomatic) multiple myeloma. Blood 2008;111:785-789). The NCCN panel strongly recommends enrolling eligible smoldering myeloma patients with high-risk criteria in clinical trials.

hsee Myeloma Therapy (MYEL-D).

isee Adjunctive Treatment (MYEL-E).
} 


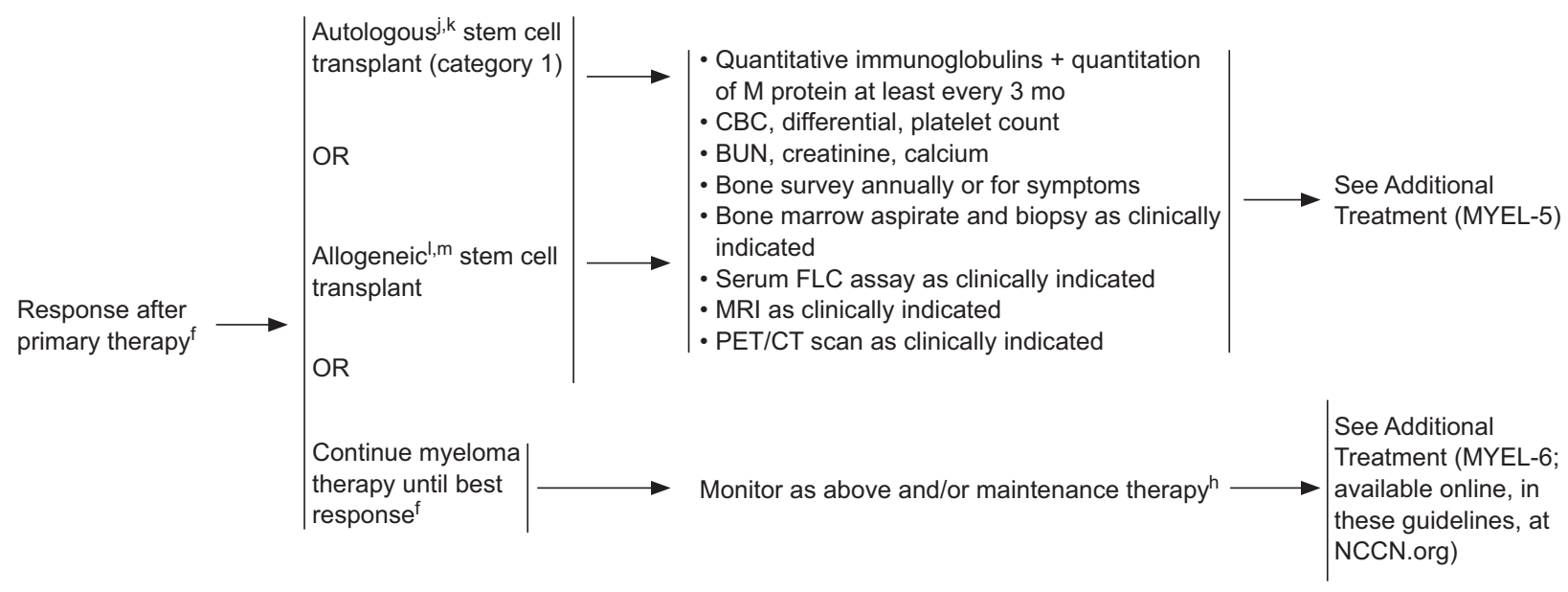

fSee Response Criteria for Multiple Myeloma (MYEL-C).

${ }^{\mathrm{h}}$ See Myeloma Therapy (MYEL-D).

${ }^{\mathrm{j} A u t o l o g o u s ~ t r a n s p l a n t a t i o n: ~ C a t e g o r y ~} 1$ evidence supports proceeding straight after induction therapy to high-dose therapy and stem cell transplant versus saving the stem cell transplant for salvage therapy. Evidence suggests equivalent overall survival, although progression-free survival can be prolonged by an early transplant. (See Discussion section).

${ }^{\mathrm{k}}$ Renal dysfunction and advanced age are not contraindications to transplant.

'Allogeneic stem cell transplant may include nonmyeloablative (mini) following autologous stem cell transplant or fully myeloablative preferably on a clinical trial. Current data do not support miniallografting alone.

$\mathrm{m}_{\mathrm{A}}$ prospective trial by Bruno et al found improved survival for patients receiving an autologous transplant followed by non-myeloablative allograft compared to patients who received tandem autologous grafts. In contrast, the IFM trial (99-03) and the BMT-CTN 0102 trial reported no overall survival or progressionfree survival with autologous transplant followed by mini-allograft in high-risk myeloma patients.

Bruno B, Rotta M, Patriarca F, et al. A comparison of allografting with autografting for newly diagnosed myeloma. N Engl J Med 2007;356:1110-1120. Garban F, Attal M, Michallet M, et al. Prospective comparison of autologous stem cell transplantation followed by dose-reduced allograft (IFM99-03 trial) with tandem autologous stem cell transplantation (IFM99-04 trial) in high-risk de novo multiple myeloma. Blood 2006;107:3474-3480.

Krishnan A, Pasquini MC, Logan B, et al. Autologous haemopoietic stem-cell transplantation followed by allogeneic or autologous haemopoietic stem-cell transplantation in patients with multiple myeloma (BMT CTN 0102): a phase 3 biological assignment trial. Lancet Oncol 2011;12:1195-1203.

Bjorkstrand B, lacobelli S, Hegenbart $U$, et al. Tandem autologous/reduced-intensity conditioning allogeneic stem-cell transplantation versus autologous transplantation in myeloma: long-term follow-up. J Clin Oncol 2011;29:3016-3022. 


\section{Post-allogeneic stem cell transplant:}

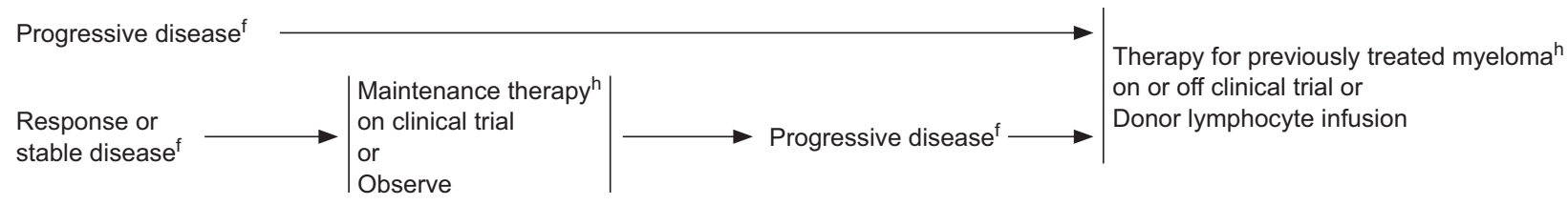

\section{$\underline{\text { Post-autologous stem cell transplant: }}$}

Progressive disease

Therapy for previously treated myeloma ${ }^{\text {h }}$ on or off clinical trial

or

Allogeneic stem cell transplant ${ }^{k}$

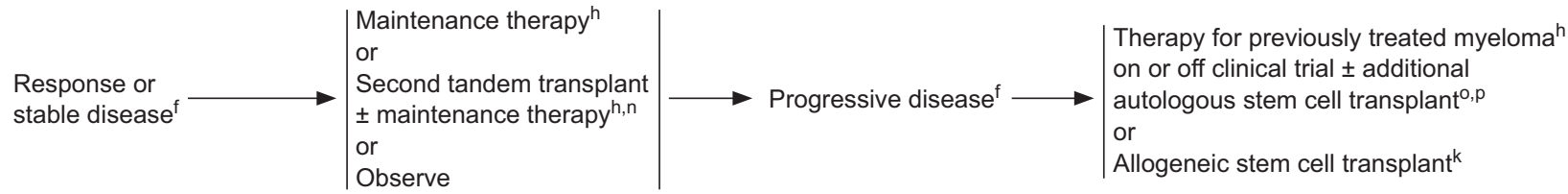

\footnotetext{
fSee Response Criteria for Multiple Myeloma (MYEL-C).

hSee Myeloma Therapy (MYEL-D; page 2 of 2 available online, in these guidelines, at NCCN.org).

kAllogeneic stem cell transplant may include nonmyeloablative (mini) following autologous stem cell transplant or fully myeloablative preferably on a clinical trial. Current data do not support miniallografting alone.

nThere is evidence from a randomized, phase III trial showing that maintenance therapy after tandem transplant significantly reduced the risk of disease progression (HR, 0.47).Palumbo A, Cavallo F, Gay F, et al. Autologous transplantation and maintenance therapy in multiple myeloma. N Engl J Med 2014;371:895-905.

${ }^{\circ}$ Additional autologous transplant on or off clinical trial is an option depending on the time interval between the preceding stem cell transplant and documented progression

PRetrospective studies suggest a 2-3 y minimum length of remission for consideration of a second autologous stem cell transplant for salvage therapy (category $2 \mathrm{~B}$ ).
}

MYEL-5

Clinical trials: NCCN believes that the best management of any cancer patient is in a clinical trial. Participation in clinical trials is especially encouraged. All recommendations are category $2 \mathrm{~A}$ unless otherwise indicated.

(C) JNCCN_Journal of the National Comprehensive Cancer Network | Volume 13 Number 11 | November 2015 
Smoldering (Asymptomatic) Myeloma ${ }^{1,2,3}$

- M-protein in serum

- $\lg \mathrm{g} \geq 3 \mathrm{~g} / \mathrm{dL}$

- $\lg A>1 \mathrm{~g} / \mathrm{dL}$

or

- Bence-Jones protein >1 g/24 h

and/or

- Bone marrow clonal plasma cells $10 \%$ - $60 \%$

- No related organ or tissue impairment (no end organ

damage, including bone lesions) or symptoms.

- If bone survey negative, assess for bone disease with whole body MRI or PET/CT
Active (Symptomatic) Myeloma ${ }^{3,4}$

$\operatorname{Re} \square$ uires one or more of the following:

- Calcium elevation ( $>11.5 \mathrm{mg} / \mathrm{dL}$ ) $\square>2.65 \mathrm{mmol} / \mathrm{L}$

- Renal insufficiency (creatinine $>2 \mathrm{mg} / \mathrm{dL}$ ) $\square 177 \square \mathrm{moll} /$ or more $\square$ or creatinine clearance $\square 40 \mathrm{~mL} / \mathrm{min}$

- Anemia (hemoglobin $\square 10 \mathrm{~g} / \mathrm{dL}$ or haemoglobin of $>2 \mathrm{~g} / \mathrm{dL}$ below the lower limit of normal)

- Bone disease (lytic or osteopenic)

- One or more bone lesions on skeletal radiography, CT, or PET-CT

or

Any one or more of the following:

- Bone marrow clonal plasma cells $\geq 60 \%$

- Abnormal Serum Free Light Chain ratio $\geq 100$ (involved kappa) or 0.01 (involved lambda)

- $>1$ focal lesions detected by functional imaging including PET/CT and/or whole body MRI

\footnotetext{
${ }^{1}$ The understanding of smoldering (asymptomatic) myeloma is evolving rapidly. Some studies have shown that patients with certain characteristics including IgG levels of $>3 \mathrm{~g} / \mathrm{dL}$, IgA of $>2 \mathrm{~g} / \mathrm{dL}$, or urinary Bence Jones protein of $>1 \mathrm{~g} / 24$ hours (Mateos MV, Hernandez M, Giraldo P, et al. Lenalidomide plus dexamethasone for high-risk smoldering multiple myeloma. N Engl J Med 2013;369:438-447) or abnormal free light chain ratios (Dispienzeri A, Kyle R, Katzmann J, et al. Immunoglobulin free light chain ratio is an independent risk factor for progression of smoldering (asymptomatic) multiple myeloma. Blood 2008;111:785-789), have an increased risk of progression to active (symptomatic) myeloma. It is also increasingly recognized, that the classical definition of smoldering myeloma using certain tests such as plain x-rays is outdated. Efforts to modify these criteria and reclassify some patients previously classified as "asymptomatic" to having "active disease" are underway.

${ }^{2}$ Criteria for the classification of monoclonal gammopathies, multiple myeloma and related disorders: a report of the International Myeloma Working Group. Br J Haematol 2003;121:749-757.

${ }^{3}$ Rajkumar SV, Dimopoulos MA, Palumbo A, et al. International Myeloma Working Group updated criteria for the diagnosis of multiple myeloma. Lancet Oncol 2014;15:e538-548.

${ }^{4}$ Other examples of active disease include: repeated infections, amyloidosis, or hyperviscosity.
}

MYEL-B 


\section{RESPONSE CRITERIA FOR MULTIPLE MYELOMA}

(Revised Uniform Response Criteria by the International Myeloma Working Group) ${ }^{1}$

\begin{tabular}{|c|c|}
\hline jory & se Criteria \\
\hline CR, complete response & $\begin{array}{l}\text { Negative immunofixation of serum and urine, disappearance of any soft tissue plasmacytomas, and }<5 \% \\
\text { plasma cells in bone marrow; in patients for whom only measurable disease is by serum FLC level, normal } \\
\text { FLC ratio of } 0.26 \text { to } 1.65 \text { in addition to CR criteria is required; } 2 \text { consecutive assessments are needed }\end{array}$ \\
\hline $\begin{array}{l}\text { SCR, stringent complete } \\
\text { response }\end{array}$ & $\begin{array}{l}\text { CR as defined plus normal FLC ratio and absence of clonal plasma cells by immunohistochemistry or 2- to } \\
\text { 4-color flow cytometry; } 2 \text { consecutive assessments of laboratory parameters are needed }\end{array}$ \\
\hline Immunophenotypic CR & $\begin{array}{l}\mathrm{sCR} \text { as defined plus absence of phenotypically aberrant plasma cells (clonal) in bone marrow with minimum of } \\
1 \text { million total bone marrow cells analyzed by multiparametric flow cytometry (with }>4 \text { colors) } \\
\end{array}$ \\
\hline Molecular CR & CR as defined plus negative allele-specific oligonucleotide polymerase chain reaction (sensitivity $10^{-5}$ ) \\
\hline $\begin{array}{l}\text { VGPR, very good partial } \\
\text { response }\end{array}$ & $\begin{array}{l}\text { Serum and urine } \mathrm{M} \text { component detectable by immunofixation but not on electrophoresis or } \geq 90 \% \text { reduction in } \\
\text { serum } \mathrm{M} \text { component plus urine } \mathrm{M} \text { component }<100 \mathrm{mg} / 24 \mathrm{~h} \text {; in patients for whom only measurable disease is } \\
\text { by serum FLC level, }>90 \% \text { decrease in difference between involved and uninvolved FLC levels, in addition to } \\
\text { VGPR criteria, is required; } 2 \text { consecutive assessments are needed }\end{array}$ \\
\hline $\mathrm{PR}$, partial & $\begin{array}{l}\geq 50 \% \text { reduction of serum M-protein and reduction in } 24 \text {-hour urinary M-protein by } \geq 90 \% \text { or to }<200 \mathrm{mg} \text { per } 24 \mathrm{~h} \\
\text { If the serum and urine M-protein are unmeasurable, a } \geq 50 \% \text { decrease in the difference between involved and } \\
\text { uninvolved FLC levels is required in place of the M-protein criteria } \\
\text { If serum and urine M-protein are unmeasurable, and serum free light assay is also unmeasurable, } \geq 50 \% \\
\text { reduction in plasma cells is required in place of M-protein, provided baseline bone marrow plasma cell } \\
\text { percentage was } \geq 30 \% \\
\text { In addition, if present at baseline, a } \geq 50 \% \text { reduction in the size of soft tissue plasmacytomas is also required. } \\
\text { Two consecutive assessments are needed; no known evidence of progressive or new bone lesions if } \\
\text { radiographic studies were performed }\end{array}$ \\
\hline $\begin{array}{l}\text { MR, minimal response } \\
\text { for relapsed refractory } \\
\text { myeloma only }\end{array}$ & $\begin{array}{l}\geq 25 \% \text { but } \leq 49 \% \text { reduction of serum } \mathrm{M} \text { protein and reduction in } 24 \text {-hour urine } \mathrm{M} \text { protein by } 50 \% \text { to } 89 \% \\
\text { In addition, if present at baseline, } 25 \% \text { to } 49 \% \text { reduction in size of soft tissue plasmacytomas is also required } \\
\text { No increase in size or number of lytic bone lesions (development of compression fracture does not exclude } \\
\text { response) }\end{array}$ \\
\hline SD, stable disease & $\begin{array}{l}\text { Not meeting criteria for CR, VGPR, PR or progressive disease; no known evidence of progressive or new bone } \\
\text { lesions if radiographic studies were performed }\end{array}$ \\
\hline PD, progressive disease & $\begin{array}{l}\text { Increase of } 25 \% \text { from lowest response value in any of following: } \\
\text { Serum M component with absolute increase } \geq 0.5 \mathrm{~g} / \mathrm{dL} \text {; serum } \mathrm{M} \text { component increases } \geq 1 \mathrm{~g} / \mathrm{dL} \text { are sufficient to } \\
\text { define relapse if starting } \mathrm{M} \text { component is } \geq 5 \mathrm{~g} / \mathrm{dL} \text { and/or; } \\
\text { Urine } \mathrm{M} \text { component (absolute increase must be } \geq 200 \mathrm{mg} / 24 \mathrm{~h} \text { ) and/or; } \\
\text { Only in patients without measurable serum and urine } \mathrm{M} \text { protein levels: difference between involved and } \\
\text { uninvolved FLC levels (absolute increase must be }>10 \mathrm{mg} / \mathrm{dL} \text { ); } \\
\text { Only in patients without measurable serum and urine } \mathrm{M} \text { protein levels and without measurable disease by FLC } \\
\text { level, bone marrow plasma cell percentage (absolute percentage must be } \geq 10 \% \text { ) } \\
\text { Development of new or definite increase in size of existing bone lesions or soft tissue plasmacytoma } \\
\text { Development of hypercalcemia that can be attributed solely to plasma cell proliferative disorder } \\
\text { Two consecutive assessments before new therapy are needed }\end{array}$ \\
\hline
\end{tabular}

Continued on MYEL-C 2 of 2, available, in these guidelines, at NCCN.org

${ }^{1}$ From Palumbo A, Rajkumar SV, San Miguel JF, et al. International Myeloma Working Group consensus statement for the management, treatment, and supportive care of patients with myeloma not eligible for standard autologous stem-cell transplantation. J Clin Oncol 2014;32:587-600

MYEL-C

1 OF 2 


\section{MYELOMA THERAPY1-3}

Exposure to myelotoxic agents (including alkylating agents and nitrosoureas) should be limited to avoid compromising stem-cell reserve prior to stem-cell harvest in patients who may be candidates for transplants.

\begin{tabular}{|c|c|c|}
\hline & Preferred Regimens & Other Regimens \\
\hline $\begin{array}{l}\text { Primary Therapy for Transplant } \\
\text { Candidates } \\
\text { (Assess for response after } 2 \text { cycles) }\end{array}$ & $\begin{array}{l}\text { - Bortezomib/dexamethasone (category } 1 \text { ) } \\
\text { - Bortezomib/cyclophosphamide/dexamethasone } \\
\text { - Bortezomib/doxorubicin/dexamethasone } \\
\text { (category 1) } \\
\text { - Bortezomib/lenalidomide } 4 / \text { dexamethasone } \\
\text { - Bortezomib/thalidomide/dexamethasone } \\
\text { (category 1) } \\
\text { - Lenalidomide } / \text { dexamethasone (category 1) }\end{array}$ & $\begin{array}{l}\text { - } \text { Carfilzomib }^{7} / \text { lenalidomide } 4 / \\
\text { dexamethasone } \\
\text { - Dexamethasone (category 2B) } \\
\text { - Liposomal } \\
\text { doxorubicin/vincristine/dexamethasone } \\
\text { (DVD) (category 2B) } \\
\text { - Thalidomide/dexamethasone } \\
\text { (category 2B) }\end{array}$ \\
\hline $\begin{array}{l}\text { Primary Therapy for } \\
\text { Non-Transplant Candidates } \\
\text { (Assess for response after } 2 \text { cycles) }\end{array}$ & $\begin{array}{l}\text { - Bortezomib/dexamethasone } \\
\text { - Bortezomib/cyclophosphamide/dexamethasone } \\
\text { - Bortezomib/lenalidomide/dexamethasone } \\
\text { - Lenalidomide/low-dose dexamethasone } \\
\text { (category 1) } \\
\text { - Melphalan/prednisone/bortezomib (MPB) } \\
\text { (category 1) } \\
\text { - Melphalan/prednisone/lenalidomide (MPL) } \\
\text { (category 1) } \\
\text { - Melphalan/prednisone/thalidomide (MPT) } \\
\text { (category 1) }\end{array}$ & $\begin{array}{l}\text { - Dexamethasone (category 2B) } \\
\text { - Liposomal } \\
\text { doxorubicin/vincristine/dexamethasone } \\
\text { (DVD) (category 2B) } \\
\text { - Melphalan/prednisone (MP) } \\
\text { - Thalidomide/dexamethasone } \\
\text { (category 2B) } \\
\text { - Vincristine/doxorubicin/ } \\
\text { dexamethasone (VAD) (category 2B) }\end{array}$ \\
\hline Maintenance Therapy & $\begin{array}{l}\text { - Bortezomib } \\
\text { - Lenalidomide }{ }^{6} \text { (category } 1 \text { ) } \\
\text { - Thalidomide (category } 1 \text { ) }\end{array}$ & $\begin{array}{l}\text { - Bortezomib } \square \text { prednisone } \\
\text { (category 2B) } \\
\text { - Bortezomib } \square \text { thalidomide } \\
\text { (category 2B) } \\
\text { - Interferon (category 2B) } \\
\text { - Steroids (category 2B) } \\
\text { - Thalidomide } \square \text { prednisone } \\
\text { (category 2B) }\end{array}$ \\
\hline
\end{tabular}

Continued on MYEL-D 2 of 2, available, in these guidelines, at NCCN.org

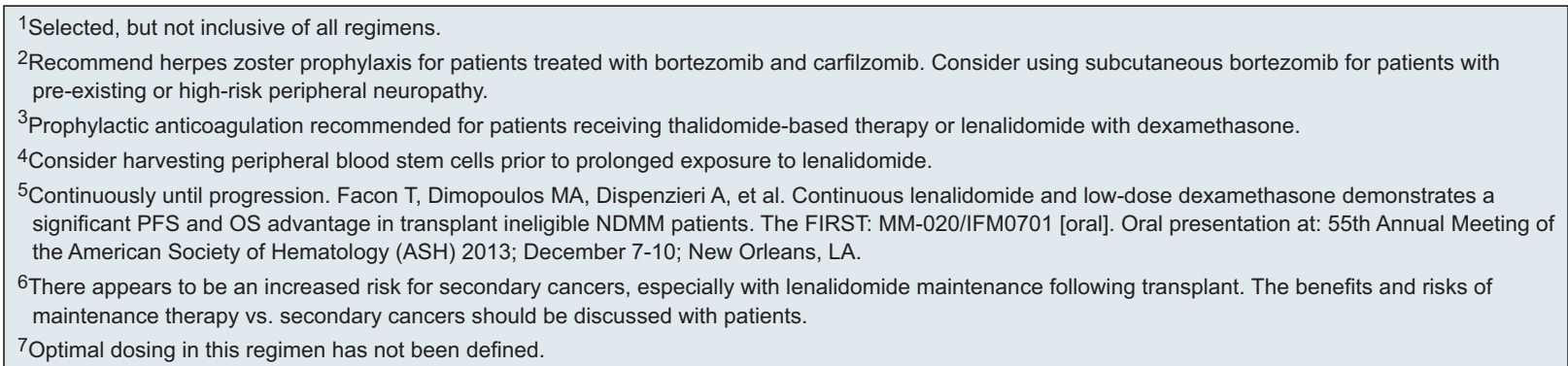




\section{ADJUNCTIVE TREATMENT}

Bone Disease

- Bisphosphonates (pamidronate and zoledronic acid)1

- All patients receiving primary myeloma therapy should be given bisphosphonates (category 1 )

$\checkmark$ A dental exam is recommended before starting bisphosphonate therapy.

- Use of bisphosphonates in smoldering or stage I disease preferably in the context of a clinical trial. These patients should have bone survey annually and if symptomatic

- Monitor for renal dysfunction with use of bisphosphonates

- Monitor for osteonecrosis of the jaw

$\cdot \mathrm{RT}$

- Low-dose RT (10-30 Gy) can be used as palliative treatment for uncontrolled pain, for impending pathologic fracture or impending cord compression

- Limited involved fields should be used to limit the impact of irradiation on stem-cell harvest or impact on potential future treatments

- Orthopedic consultation should be sought for impending or actual long-bone fractures or bony compression of spinal cord or vertebral column instability

- Consider vertebroplasty or kyphoplasty for symptomatic vertebral compression fractures

\section{Hypercalcemia}

- Hydration/furosemide, bisphosphonates (zoledronic acid preferred), steroids, and/or calcitonin.

\section{Hyperviscosity}

- Plasmapheresis should be used as adjunctive therapy for symptomatic hyperviscosity
Anemia

- See NCCN Guidelines for Cancer- and Chemotherapy-Induced

Anemia (available at NCCN.org)

- Consider erythropoietin for anemic patients

Infection

- See NCCN Guidelines for Prevention and Treatment of CancerRelated Infections (available at NCCN.org)

- Intravenous immunoglobulin therapy should be considered in the setting of recurrent life-threatening infection

- Consider pneumococcal polysaccharide vaccine and influenza vaccine

- PCP, herpes, and antifungal prophylaxis if high-dose dexamethasone regimen

- Herpes zoster prophylaxis for patients treated with bortezomib

Renal Dysfunction

- Maintain hydration to avoid renal failure

- Avoid use of NSAIDs

- Avoid IV contrast

- Plasmapheresis (category 2B)

- Not a contraindication to transplant

- Monitor for renal dysfunction with chronic use of bisphosphonates

\section{Coagulation/thrombosis}

- Prophylactic anticoagulation recommended for patients receiving thalidomide-based, or lenalidomide with dexamethasone therapy

- See NCCN Guidelines for Venous Thromboembolic Disease (available at NCCN.org) 
the following urine and serum analyses: urine analysis as a part of the initial diagnostic workup includes evaluating 24-hour urine for total protein; urine protein electrophoresis (UPEP), and urine immunofixation electrophoresis (UIFE).

Serum analysis also includes quantitative immunoglobulin levels of different types of antibodies (IgG, IgA, and IgM); serum protein electrophoresis (SPEP); and serum immunofixation electrophoresis (SIFE) to obtain more specific information about the type of abnormal antibodies present. Assessing changes and proportions of various proteins, particularly the M-protein, helps track the progression of myeloma disease and response to treatment. Use of serum free light chain (FLC) assay along with SPEP and SIFE yields high sensitivity while screening for MM and related plasma cell disorders. ${ }^{7}$ Therefore, this assay is now included as a part of the initial diagnostic workup in the NCCN Clinical Practice Guidelines in Oncology (NCCN Guidelines) for Multiple Myeloma. The serum FLC assay also has prognostic value in plasma cell disorders, including monoclonal gammopathy of undetermined significance (MGUS), smoldering myeloma, active myeloma, immunoglobulin light chain amyloidosis, and solitary plasmacytoma., ${ }^{7,8}$ The serum FLC assay also allows for quantitative monitoring of patients with light chain amyloidosis and oligosecretory myeloma. In addition to all of the previously stated, the FLC ratio is required for documenting stringent complete response ( $\mathrm{sCR}$ ) according to the International $\mathrm{My}$ eloma Working Group (IMWG) Uniform Response Criteria. ${ }^{9}$ The FLC assay cannot replace the 24-hour UPEP for monitoring patients with measurable urinary $\mathrm{M}$-proteins.

Most patients have serum proteins with or without associated urinary protein. In the Mayo Clinic review of 1027 patients newly diagnosed with MM, $20 \%$ of patients had secretory urinary proteins; however, $3 \%$ of patients had neither serum nor urine proteins, and therefore had nonsecretory myeloma. ${ }^{10}$ The serum FLC assay is useful to monitor disease response and progression in a proportion of patients with nonsecretory myeloma. After the myeloma or M-protein is quantified, it is important to use the same test for serial studies to ensure accurate relative quantification.

To evaluate bone marrow plasma cell infiltration, bone marrow aspiration and biopsy is recom- mended to detect quantitative and/or qualitative abnormalities of bone marrow plasma cells. To evaluate lytic bone lesions, full skeleton radiographic survey is recommended.

Although MM may be morphologically similar, several subtypes of the disease have been identified at the genetic and molecular level. Bone marrow studies at initial diagnosis should include chromosome analysis by conventional karyotyping (cytogenetics) and fluorescence in situ hybridization (FISH) performed with the plasma cells obtained from bone marrow aspiration. Specific chromosomal abnormalities have been identified in patients with MM involving translocations, deletions, or amplifications.

Deletion of chromosome 13 [del(13)] seems to have an amplifying effect on cell cycle gene expression and is reported to be associated with short event-free survival (EFS) and overall survival (OS). ${ }^{11}$ Deletion of $17 \mathrm{p} 13$ (the locus for the tumorsuppressor gene, p53) leads to loss of heterozygosity of TP53 and is considered a high-risk feature in MM. ${ }^{12-14}$ Other high-risk chromosomal aberrations in $\mathrm{MM}$ are characterized by structural changes that include specific rearrangements involving the $I G H$ gene (encoding immunoglobulin heavy chain), located at $14 \mathrm{q} 32$. Several subgroups of patients are identified on the basis of $14 \mathrm{q} 32$ translocations. The 3 main translocations are the $t(11 ; 14)(q 13 ; q 32)$; $\mathrm{t}(4 ; 14)(\mathrm{p} 16 ; \mathrm{q} 32)$; and $\mathrm{t}(14 ; 16)(\mathrm{q} 32 ; \mathrm{q} 23)$. From a clinical point of view, $\mathrm{t}(4 ; 14)$ is the most important. Several studies have confirmed that patients with this translocation have a poor prognosis. ${ }^{15-17}$ Conflicting data exist regarding $\mathrm{t}(14 ; 16)$; although one study showed no impact on prognosis, ${ }^{18}$ some studies have shown a negative prognostic impact. ${ }^{19,20}$

A translocation between 11 and 14 [t $(11 ; 14)]$ has been reported to be associated with an improved survival. ${ }^{21,22}$ Abnormalities of chromosome 1 are also among the frequent chromosomal alterations in MM. ${ }^{23}$ The short arm is most often associated with deletions and the long arm with amplifications. ${ }^{24}$ Gains/amplification of 1q21 increases the risk of MM progression and incidence of the amplification is higher in relapse than in newly diagnosed MM..$^{23,25}$

Stratification of patients into various risk groups based on the chromosomal markers is being used by some centers for prognostic counseling, selection, and sequencing of therapy approaches. ${ }^{26,27}$ According to 
the NCCN Multiple Myeloma Panel, the FISH panel for prognostic estimation should include $t(4 ; 14)$, $\mathrm{t}(14 ; 16)$, and $17 \mathrm{p} 13$ deletions, $\mathrm{t}(11 ; 14)$, chromosome 13 deletion, and chromosome 1 amplification. The utility of this information is to determine biologic subtype and for prognostic recommendations.

In addition to cytogenetic markers of prognosis, it is postulated that biologic factors or gene expression signatures may be capable of discerning prognosis and helping rational therapeutic decisions. ${ }^{28,29}$ Further understanding of the molecular subtypes of $\mathrm{MM}$ is emerging from the application of highthroughput genomic tools such as gene expression profiling (GEP).$^{30}$ With the currently available novel treatment approaches, most patients with MM can anticipate long-term disease control. However, patients with cytogenetically and molecularly defined high-risk disease do not receive the same benefit from certain approaches as the patients with lowrisk disease and need alternative therapies. GEP is a powerful and fast tool with the potential to provide additional prognostic value to further refine risk stratification, help therapeutic decisions, and inform novel drug design and development. Several groups have identified and developed 15-gene, 70-gene, and 92-gene models based on GEP signatures of MM cells. ${ }^{31-33}$ Studies show that patients in the high-risk group based on the 15 -gene, ${ }^{31} 70$-gene, ${ }^{32}$ or 92 -gene ${ }^{33}$ models had shorter survival compared with the lowrisk group. The NCCN Panel unanimously agreed that although GEP is not currently routinely used in clinical practice during diagnostic workup, it is a useful tool and may be helpful in selected patients to estimate the aggressiveness of the disease and individualize treatment.

Bone marrow immunohistochemistry may be useful in some cases to confirm presence of monoclonal plasma cells and to more accurately quantify plasma cell involvement, and bone marrow flow cytometry can help define the disease.

\section{Additional Diagnostic Tests}

The NCCN Multiple Myeloma Panel recommends additional tests that may be useful under some circumstances. These include MRI, ${ }^{34} \mathrm{CT}$, and PET/ CT scan. ${ }^{35}$ Active myeloma is positive on PET scan. ${ }^{36,37}$ PET/CT and MRI scans are more sensitive than plain radiographs and are only indicated when symptomatic areas show no abnormality on routine radiographs. A multivariate analysis showed persis- tent fluorodeoxyglucose PET/CT positivity before and after primary therapy and subsequent high-dose therapy, and is a predictor of prognosis in patients with symptomatic MM. . $^{38,39}$

A tissue biopsy may also be necessary to confirm the presence of plasmacytomas. Plasma cell labeling index may be helpful to identify the fraction of the myeloma cell population that is proliferating. ${ }^{40} \mathrm{Also}$, bone marrow and fat pad staining for the presence of amyloid and serum viscosity should be evaluated if hyperviscosity is suspected.

In selected patients with MM, physicians may use allogeneic (ie, from someone else) transplantation. In this approach, physicians administer nonmyeloablative or reduced intensity therapy and infuse stem cells (ie, peripheral blood or bone marrow) obtained from a donor, preferably a human leukocyte antigen (HLA)identical sibling. In such cases, the patient will need to be HLAtyped.

Since bisphosphonate therapy is a consideration in patients with MM, a baseline bone densitometry test may be recommended.

\section{Diagnostic Categories}

Based on the results of the clinical and laboratory evaluation discussed in previous sections, patients are initially classified as either having smoldering (asymptomatic) disease or active (symptomatic) disease. For definitions refer to the NCCN Guidelines for Multiple Myeloma section titled "Definition of Multiple Myeloma (Smoldering and Active)," page 1405.

The IMWG recently updated the disease definition of MM to include biomarkers in addition to existing requirements of cancer research and biostatistics (CRAB) features. ${ }^{41}$ The CRAB criteria that define $\mathrm{MM}$ include hypercalcemia $(>11.5 \mathrm{mg} / \mathrm{dL})$, renal insufficiency (creatinine $>2 \mathrm{mg} / \mathrm{dL}$ ), anemia (hemoglobin $<10 \mathrm{~g} / \mathrm{dL}$ or $2 \mathrm{~g} / \mathrm{dL}<$ normal), and presence of bone lesions. The IMWG has also clarified that the presence of one or more osteolytic lesions seen on skeletal radiography, whole body MRI, or PET-CT fulfils the criteria for bone disease. ${ }^{41}$ The MM defining biomarkers identified by the IMWG include one or more of the following: $60 \%$ or more clonal plasma cells in the bone marrow; involved/ uninvolved FLC ratio of 100 or more with the involved FLC being $100 \mathrm{mg} / \mathrm{L}$ or more; MRI with more than one focal lesion (involving bone or bone marrow). ${ }^{41}$ 
The criteria by the IMWG for (asymptomatic) patients with smoldering $\mathrm{MM}$ include serum monoclonal protein (IgG or IgA) $30 \mathrm{~g} / \mathrm{L}$ or more and/or clonal bone marrow plasma cells $10 \%$ to $60 \%$ and absence of myeloma-defining events or amyloidosis. ${ }^{41}$ The updated IMWG diagnostic criteria for MM helps to initiate therapy before end-organ damage on the basis of specific biomarkers and also allows the use of sensitive imaging criteria to diagnose MM, including PET/CT and MRI. ${ }^{41}$ Patients with high-risk soldering myeloma, who are being observed at 3 to 6 month intervals with sensitive imaging techniques as clinically indicated, can be started on therapy without waiting for CRAB features to appear.

Patients with active myeloma can be categorized according to stage, based on either the DurieSalmon staging system or the International Staging System (ISS). ${ }^{42}$ The ISS system is based on easily obtained laboratory measures (serum beta 2 microglobulin and serum albumin) and is easier to use than the DurieSalmon staging system for patients with previously untreated MM.

\section{Response Criteria}

Assessing the response to treatment is a key determinant of myeloma treatment. The IMWG response criteria were developed from the European Group for Blood and Marrow Transplant/International Bone Marrow Transplant Registry/Autologous Blood and Bone Marrow Transplant Registry (EBMT/IBMTR/ ABMTR) response criteria, ${ }^{43}$ with revisions and improvements to help uniform reporting.

The updated IMWG response criteria definitions $^{9,44,45}$ for complete response (CR), sCR, immunophenotypic CR, molecular CR, very good partial response (VGPR), partial response (PR), MR for relapsed refractory myeloma, stable disease (SD), and progressive disease (PD) are outlined in the NCCN Guidelines for Multiple Myeloma section titled "Response Criteria for Multiple Myeloma” (MYEL-C 1 of 2, page 1406). It is recommended that the IMWG uniform response criteria be used in future clinical trials.

\section{Solitary Plasmacytoma}

The diagnosis of solitary plasmacytoma requires a thorough evaluation to rule out the presence of sys- temic disease, because many patients presumed to have solitary plasmacytomas are found to have occult disease. Solitary plasmacytomas are further categorized as osseous or extraosseous. Osseous plasmacytoma is defined as a plasmacytoma emanating from bone without other evidence of disease. Solitary plasmacytomas derived from soft tissue are termed extraosseous. ${ }^{46}$ An analysis of the SEER database between 1992 and 2004 found that incidence of osseous plasmacytoma was $40 \%$ higher than extraosseous plasmacytoma $(P<.0001) .{ }^{47}$

\section{Primary Therapy for Solitary Plasmacytoma}

The treatment and follow-up options for osseous and extraosseous plasmacytomas are similar. Radiation therapy (RT) has been shown to provide excellent local control of solitary plasmacytomas. ${ }^{48-54}$ The largest retrospective study $(\mathrm{N}=258)$ included patients with solitary plasmacytoma $(n=206)$ or extramedullary plasmacytoma $(\mathrm{n}=52) .{ }^{55}$ Treatments included RT alone $(n=214)$, RT plus chemotherapy $(n=34)$, and surgery alone $(n=8)$. Five-year $\mathrm{OS}$ was $74 \%$, diseasefree survival was $50 \%$, and local control was $85 \%$. Patients who received localized RT had a lower rate of local relapse (12\%) than those who did not (60\%). ${ }^{54}$

The optimal radiation dose for treatment of solitary plasmacytomas is not known. The median dose used in most published papers is 40 Gy with doses ranging from 30 to $60 \mathrm{~Gy}{ }^{53,54,56}$

For those patients with osseous plasmacytoma, the NCCN Panel recommends that primary RT ( $>30$ Gy to the involved field) to the involved field is the initial treatment and is potentially curative. For extraosseous plasmacytomas, primary treatment is RT ( $>30$ Gy to the involved field $)^{51}$ to the involved field followed by surgery ${ }^{57}$ if necessary.

\section{Surveillance/Follow-up Tests for Solitary Plasmacytoma}

Follow-up and surveillance tests for both solitary plasmacytoma and extraosseous plasmacytoma consist of blood and urine tests. Serial and frequent measurements of M-protein are required to confirm disease sensitivity. The blood tests include CBC; serum chemistry for creatine, albumin, and corrected calcium; serum quantitative immunoglobulins, SPEP, and SIFE; and serum FLC assay. Testing for LDH levels and beta2 microglobulin may be useful under some circumstances. The urine tests include 24-hour urine assay for total protein, UPEP, and UIFE. 
Bone marrow aspirate and biopsy and imaging studies using MRI and/or CT and/or PET/CT are recommended as clinically indicated. PET imaging may detect early bone marrow involvement in patients with solitary plasmacytoma. ${ }^{37,58,59}$ Bone survey is recommended annually or as clinically indicated. If PD emerges, then the patient should be reevaluated as described in "Initial Diagnostic Workup" (MYEL-1; page 1400), and systemic therapy must be administered as indicated.

\section{Smoldering (Asymptomatic) Myeloma}

Smoldering (asymptomatic) myeloma describes a stage of disease with no symptoms and no related organ or tissue impairment. ${ }^{60}$ Patients with Durie-Salmon stage I myeloma with low amounts of M-protein without significant anemia, hypercalcemia, or bone disease would be included in this category. Patients with asymptomatic smoldering MM may have an indolent course for many years without therapy.

\section{Primary Therapy for Smoldering (Asymptomatic) Multiple Myeloma}

Patients with smoldering myeloma, including DurieSalmon stage I, do not need primary therapy as it may take many months to years before the disease progresses. The risk of transformation to symptomatic myeloma ${ }^{61}$ in these patients is life long and therefore they should be followed up closely.

A relatively small, randomized, prospective, phase III study by the PETHEMA group investigated whether early treatment with lenalidomide and dexamethasone in patients $(n=125)$ with smoldering myeloma at high risk of progression to active $\mathrm{MM}$, prolongs the time to progression. ${ }^{62}$ The high-risk group in the study was defined using the following criteria: plasmacell bone marrow infiltration of at least $10 \%$ and/or a monoclonal component (defined as an IgG level of $\geq 3$ $\mathrm{g} / \mathrm{dL}$, an IgA level of $\geq 2 \mathrm{~g} / \mathrm{dL}$, or a urinary Bence Jones protein level of $>1 \mathrm{~g}$ per 24 hours), and at least 95\% phenotypically aberrant plasma cells in the bone marrow infiltrate. At a median follow-up of 40 months (range, 27-57 months), treatment with lenalidomide and dexamethasone delayed median time to progression to symptomatic disease compared with no treatment (time to progression was not reached in the treatment arm compared with 21 months in the observation arm; hazard ratio [HR], 0.18; 95\%
CI, 0.09-0.32; $P<.001)$. The OS reported in the trial at 3 years was higher in the lenalidomide and dexamethasone arm $(94 \%$ vs $80 \%$; HR, 0.31; $95 \% \mathrm{CI}$, $0.10-0.91 ; P=.03) .{ }^{62}$

According to the NCCN Panel, the high-risk criteria specified in the study are not currently in common use. Based on the criteria used in the trial, some patients with active myeloma were classified as having high-risk smoldering myeloma. This fact is evident from the striking differences in outcome seen between patients who were treated and those who were only observed. The NCCN Panel strongly believes there is need to re-evaluate the definition of high-risk smoldering myeloma. The panel believes that it is too early to begin treating all patients with smoldering myeloma at high risk (as defined in the trial) of progression to active MM with any antimyeloma therapy. The panel recommends that patients with smoldering myeloma should initially be observed at 3- to 6-month intervals (category 1 recommendation) or strongly recommends enrolling eligible patients with smoldering myeloma in clinical trials.

\section{Surveillance/Follow-up Tests for Smoldering (Asymptomatic) Multiple Myeloma}

The surveillance/follow-up tests include CBC; serum chemistry for creatinine, albumin, LDH, calcium, and beta 2 microglobulin; serum quantitative immunoglobulins, SPEP, and SIFE; and serum FLC assay. The urine tests include 24-hour urine assay for total protein, UPEP, and UIFE.

Bone survey is recommended annually or as clinically indicated. Bone marrow aspiration and biopsy and imaging studies with MRI and/or CT and/or PET/CT are recommended as clinically indicated. ${ }^{63}$ PET imaging seems to reliably predict active myeloma; by virtue of FDG uptake, lowlevel smoldering myeloma is consistently negative on the PET scan. ${ }^{36}$ It can also be used to assess the extent of active disease, detect extramedullary involvement, and evaluate treatment response. ${ }^{37,64-66}$

Multiparameter flow cytometry is a tool that can help individualize the follow-up/surveillance strategy for patients with smoldering myeloma. It measures abnormal cells in the bone marrow and provides information regarding the risk of progression to active myeloma. A high proportion of abnormal plasma cells within the bone marrow plasma cell compartment $(>95 \%)$ has been shown to predict the risk of 
progression in patients with smoldering myeloma or MGUS, as has quantity and type of $M$ protein (non$\mathrm{IgG}$ ) and abnormal serum FLC assay. ${ }^{67,68}$ According to the NCCN Multiple Myeloma Panel, multiple parameter flow cytometry information may be a useful consideration in the follow-up/surveillance plan for patients with smoldering myeloma. However, because this test is not standardized and is widely available, they recommend that it should only be performed in laboratories with experience.

If the disease progresses to symptomatic myeloma, then patients should be treated according to the guidelines for symptomatic MM. The IMWG definition for PD is in the section titled "Response Criteria for Multiple Myeloma” (MYEL-C 1 of 2, page 1406).

\section{Active (Symptomatic) Multiple Myeloma}

\section{Primary Therapy for Active (Symptomatic) MM}

Patients presenting with active (symptomatic) myeloma are initially treated with primary therapy and, in selected patients, primary therapy is followed with high-dose chemotherapy with autologous stem cell support. Stem cell toxins, such as nitrosoureas or alkylating agents, may compromise stem cell reserve, and regimens with these agents (notably melphalan) should be avoided in patients who are potential candidates for stem cell transplant (SCT). Therefore, one of the first steps in evaluating patients with advanced $\mathrm{MM}$ is to determine whether they are candidates for high-dose therapy and transplant, based on age and comorbidities. However, it should be noted that advanced age and renal dysfunction are not absolute contraindications to transplant. It is also important to consider supportive care for all patients at diagnosis. For example, $80 \%$ of patients have bone disease and up to $33 \%$ have renal compromise. Bone disease, renal dysfunction, and other complications such as hypercalcemia, hyperviscosity, and coagulation/thrombosis should be treated with appropriate adjunctive measures (see "Adjunctive Treatment for Multiple Myeloma,” MYEL-E, page 1408). In all patients, careful attention to supportive care is critical to avoid early complications that may compromise therapeutic outcome.

"Myeloma Therapy" (page 1407) in the guidelines includes a list of primary therapy regimens recommended by the panel for transplant and nontransplant candidates and also lists drugs recommended for maintenance therapy. The list is not inclusive of all regimens. The NCCN Multiple Myeloma Panel classified the regimens either as "preferred regimens" or "other regimens" on the basis of a balance of efficacy and toxicity. Research into various primary regimens has focused on improving the $\mathrm{CR}$ rates in both transplant and non-transplant candidates. The NCCN Panel has noted the importance of assessing for response to primary therapy after 2 cycles.

Lenalidomide is a potent analogue of thalidomide. Both lenalidomide and thalidomide possess immunomodulatory properties. ${ }^{69}$ Prophylaxis with an anticoagulation agent is recommended for patients receiving thalidomide or lenalidomidebased therapy.

Bortezomibbased regimens may be of value in patients with renal failure and in those with certain adverse cytogenetic features. ${ }^{70}$ Bortezomib treatment has been associated with an increased incidence of herpes zoster. ${ }^{71-73}$ The incidence of bortezomibassociated herpes zoster may be reduced with the use of prophylactic acyclovir. ${ }^{74}$ The risk of deep vein thrombosis (DVT) is low with bortezomib; however, peripheral neuropathy and gastrointestinal disturbance can be higher. Bortezomib-related adverse events are predictable and managed with patient monitoring and appropriate supportive care. ${ }^{75}$

\section{Preferred Primary Therapy Regimens for Transplant Candidates}

Bortezomib/Dexamethasone: In the IFM cooperative group trial, 482 transplant-eligible patients were randomized to one of the following 4 primary therapy arms: 1) vincristine, doxorubicin, and dexamethasone (VAD; $\mathrm{n}=121$ ) alone; 2) VAD plus consolidation therapy with dexamethasone, cyclophosphamide, etoposide, cisplatin (DCEP; $n=121$ ); 3) bortezomib and dexamethasone $(n=121)$; or 4$)$ bortezomib, dexamethasone plus consolidation with $\operatorname{DCEP}(\mathrm{n}=119) .{ }^{76}$ The primary endpoint was response rate after primary therapy. The investigators evaluated the response according to modified EBMT criteria, ${ }^{43}$ including additional categories of near CR (CR but immunofixationpositive) ${ }^{77}$ and VGPR (serum M-protein reduction $\geq 90 \%$; urine light chain $<100$ $\mathrm{mg} / 24$ hours). ${ }^{9}$ After primary therapy, the overall response rate (ORR; $78.5 \%$ vs $62.8 \%$ ) and the rates of CR/near CR (14.8\% vs $6.4 \%)$ and VGPR $(37.7 \%$ vs $15.1 \%$ ) were significantly higher with bortezo- 
mib plus dexamethasone versus VAD. ${ }^{76}$ At a median follow-up of 32.2 months, median progression-free survival (PFS) was modestly but not statistically significantly prolonged, with 36.0 months with bortezomib and dexamethasone versus 29.7 months with VAD.${ }^{76}$ Use of DCEP as consolidation therapy after primary therapy did not have a significant impact on response rates. ${ }^{76}$ Bortezomib and dexamethasone regimen was equally effective in patients with highrisk MM, including those with ISS stage III disease and poor-risk cytogenetic abnormalities. The incidence of severe adverse events reported was similar between the two groups. Hematologic toxicity and deaths related to toxicity were more frequent with VAD versus bortezomib and dexamethasone (7 vs $0)$. The rates of grade $2(20.5 \%$ vs $10.5 \%)$ and grades 3 to $4(9.2 \%$ vs $2.5 \%)$ peripheral neuropathy during induction through first transplantation were significantly higher with bortezomib and dexamethasone compared with VAD. ${ }^{76}$

The IFM conducted a phase III randomized trial comparing bortezomib and dexamethasone with a combination of reduced doses of bortezomib and thalidomide plus dexamethasone. ${ }^{78}$ The response rates achieved in the comparing bortezomib and dexamethasone arm seen in this study match those described in previous trials comparing VAD with bortezomib and dexamethasone. ${ }^{76}$

Patients with either $t(4 ; 14)$ or $\operatorname{del}(17 \mathrm{p})$ are known to have a short EFS and OS. A study analyzed a large series of patients (younger 65 years) with newly diagnosed transplant-eligible MM treated and $t(4 ; 14)$ or $\operatorname{del}(17 \mathrm{p})$ treated with bortezomib and dexamethasone versus VAD as primary therapy before treatment. ${ }^{70}$ The analysis showed that bortezomib improves the prognosis (in terms of both EFS and OS; $P<.001$ and $P<.001$, respectively) of patients with $\mathrm{t}(4 ; 14)$ compared with patients treated with VAD primary therapy. ${ }^{70}$

Based on these data and the uniform consensus among the NCCN Multiple Myeloma Panel Members, bortezomib and dexamethasone is listed as a category 1 primary therapy option for transplanteligible patients with MM. The panel recommends herpes prophylaxis in patients receiving bortezomib therapy.

Bortezomib/Doxorubicin/Dexamethasone: The updated results from the HOVON65/GMMGHD4 group phase III trial of newly diagnosed patients with stage II/III MM demonstrated high response rates after primary therapy with the bortezomib, doxorubicin, and dexamethasone versus VAD, and this superior response rate (CR + near CR was 31\% vs $15 \% ; P<.001)$ was maintained even after SCT with significantly higher ORR. ${ }^{79}$ No unexpected toxicities occurred, and del(13q) did not have a significant impact on response. Response rates improved with bortezomib maintenance (34\% vs $49 \%$; P<.001) ${ }^{79}$ After a median follow-up of 41 months, PFS in patients treated with bortezomib, doxorubicin, and dexamethasone as primary therapy followed by SCT and bortezomib maintenance was 35 months versus 28 months in patients treated with VAD followed by SCT and maintenance with thalidomide. Patients treated with bortezomib, doxorubicin, and dexamethasone had a significantly better PFS (HR, $0.75 ; 95 \% \mathrm{CI}, 0.62-0.90 ; P=.002) .{ }^{79}$ The OS was also found to be better in the bortezomib, doxorubicin, and dexamethasone arm (HR, 0.77; 95\% CI, $0.60-1.00 ; P=.049)$. In patients at high risk presenting with increased creatinine more than $2 \mathrm{mg} / \mathrm{dL}$, bortezomib significantly improved PFS from a median of 13 months to 30 months (HR, 0.45; 95\% CI, $0.26-0.78 ; P=.004)$ and OS from a median of 21 months to 54 months (HR, 0.33; 95\% CI, 0.16$0.65 ; P<.001)$. A benefit in terms of increased PFS was also seen in patients with deletion of $17 \mathrm{p} 13 .{ }^{79}$ The rate of grade 2 to 4 peripheral neuropathy was higher in those treated with the bortezomib-containing regimen versus VAD (40\% vs $18 \%$ ). In addition, grade 3 to 4 peripheral neuropathy occurred in $8 \%$ of patients during thalidomide maintenance and $5 \%$ of patients during bortezomib maintenance. ${ }^{79}$

Based on data from the HOVON65/GMMGHD4 trial and the uniform consensus among the NCCN Multiple Myeloma Panel Members, the bortezomib, doxorubicin, and dexamethasone regimen is a category 1 option for primary therapy for transplant-eligible patients with MM.

Bortezomib/Thalidomide/Dexamethasone: Thalidomide attacks multiple targets in the microenvironment of the myeloma cell, producing apoptosis, inhibition of angiogenesis, and cytokine circuits, among others. The GIMEMA Italian Multiple Myeloma Network reported results of a phase III trial investigating bortezomib, thalidomide, and dexamethasone $(n=241)$ versus thalidomide and dexamethasone $(n=239)$ as primary therapy, followed by 
tandem autologous SCT with high-dose melphalan and then consolidation therapy with the same primary regimen. ${ }^{80}$ The addition of bortezomib to thalidomide and dexamethasone significantly improved ORR after primary treatment. After primary therapy, $\mathrm{CR} /$ near CR was achieved in 73 patients (31\%; $95 \%$ CI, 25.0-36.8) receiving bortezomib, thalidomide, and dexamethasone, and 27 patients $(11 \%, 95 \% \mathrm{CI}$, 7.3-15.4) on thalidomide/dexamethasone. ${ }^{80}$ Rates of $\mathrm{CR} /$ near CR and VGPR or better continued to be significantly higher in the bortezomib, thalidomide, and dexamethasone group than in the thalidomide/ dexamethasone group after the first and second autologous SCT, and subsequent consolidation therapy. ${ }^{80}$ Patients receiving the bortezomib-containing regimen experienced grade $3 / 4$ peripheral neuropathy.

Data from a single-institution retrospective study are similar to the interim data from the GIMEMA trial. ${ }^{81}$ The findings of this analysis demonstrate that ORR after primary therapy with bortezomib, thalidomide, and dexamethasone was $94 \%$ of the patients (32 of 34 patients showed some response, including a VGPR rate $\geq 56 \%$ ). ${ }^{81}$

The results of the randomized phase III trial by the Spanish Myeloma Group (PETHEMA/GEM) also demonstrated a significantly higher $\mathrm{CR}$ rate with bortezomib, thalidomide, and dexamethasone as primary therapy overall (35\% vs $14 \% ; P=.001)$ and in patients with high-risk cytogenetics (35\% vs $0 \% ; P=.002) .82$ The $\mathrm{CR}$ rate continued to be significantly higher after autologous SCT (46\% vs $24 \%)$ in patients treated with bortezomib, thalidomide, and dexamethasone versus thalidomide and dexamethasone as primary therapy. ${ }^{82}$

Based on the previously cited data and the uniform consensus among the NCCN Multiple Myeloma Panel Members, the bortezomib, thalidomide, and dexamethasone regimen is a category 1 option as primary therapy for transplant-eligible patients with MM.

\section{Cyclophosphamide/Bortezomib/Dexamethasone:}

Data from 3 phase II studies involving newly diagnosed patients with MM have shown high response rates with cyclophosphamide, bortezomib, and dexamethasone (CyBorD) as primary treatment. ${ }^{83-85}$ The trial by Reeder et $\mathrm{al}^{83}$ performed in the United States and Canada demonstrated an ORR of $88 \%$, including a VGPR or greater of $61 \%$ and $39 \%$ CR/ near CR with CyBorD as the primary regimen. The depth of response seen after primary treatment was maintained after transplant in those who underwent transplantation (70\% rates of $\mathrm{CR} /$ near $\mathrm{CR}$; rate of at least VGPR or better was 74\%). ${ }^{83}$ According to the long-term follow-up analysis, the 5-year PFS and OS rates were $42 \%$ (95\% CI, 31\%-57\%) and 70\% (95\%CI, 59\%-82\%). ${ }^{86}$

Analysis of the German DSMM XIa study also demonstrated high responses with CyBorD as primary treatment (ORR was $84 \%$; with $74 \%$ PR rate and $10 \%$ $\mathrm{CR}$ rate). High response rates were seen in patients with unfavorable cytogenetics. ${ }^{84}$ In the updated results of the phase II EVOLUTION study, primary treatment with CyBorD demonstrated ORR of 75\% (22\% CR and $41 \% \geq$ VGPR), and 1 -year PFS rate was $93 \% .85$

Based on data from these 3 phase II studies, the NCCN Multiple Myeloma Panel has now included the combination of CyBorD as a category $2 \mathrm{~A}$ recommendation to the list of primary treatment options available for transplant candidates.

Twice-weekly bortezomib can be associated with toxicities that may limit efficacy caused by treatment delays or discontinuation. Therefore, Reeder et $\mathrm{al}^{87}$ modified the regimen to a once-weekly schedule of bortezomib. In the study, patients treated with weekly bortezomib experienced responses similar to the twice-weekly schedule (ORR, 93\% vs $88 \%$; VGPR, $60 \%$ vs $61 \%$ ). In addition, they experienced fewer grade $3 / 4$ adverse events $(37 \% / 3 \%$ vs $48 \% / 12 \%)$. Fewer dose reductions of bortezomib and dexamethasone were required in the modified schedule, and neuropathy rates were the same in both cohorts, even though the total bortezomib dose per cycle was higher in the weekly versus the twice-weekly schedule $\left(6.0 \mathrm{mg} / \mathrm{m}^{2}\right.$ vs $\left.5.2 / \mathrm{mg} / \mathrm{m}^{2}\right){ }^{87}$

Lenalidomide/Dexamethasone: Lenalidomide is a potent analogue of thalidomide. Like thalidomide, it is believed to attack multiple targets in the microenvironment of the myeloma cell, producing apoptosis and inhibition of angiogenesis and cytokine circuits, among others. Lenalidomide received approval from the US FDA for the treatment of relapsed/refractory MM in combination with dexamethasone. Lenalidomide and dexamethasone have also been investigated as primary therapy. The phase III randomized controlled study, S0232, by SWOG compared dexamethasone single-agent with dexamethasone plus lenalidomide for patients newly diagnosed with $\mathrm{MM}^{88}$ 
Multiple Myeloma, Version 2.2016

This trial was halted at interim analysis and patients on dexamethasone alone were allowed to switch to lenalidomide with dexamethasone. The SWOG data and safety monitoring committee based its recommendation to permanently close enrollment based on the preliminary results from the ECOG phase III study (E4A03). ${ }^{89}$ At the time the SWOG trial was halted - at the end of 1 year - the lenalidomide plus dexamethasone arm showed improved CR rate compared with dexamethasone alone $(22.1 \%$ vs $3.8 \%) .{ }^{88}$

In an open-label trial, 445 patients with newly diagnosed MM were randomly assigned to high-dose or low-dose regimens. The response was superior with high-dose dexamethasone. One hundred sixty-nine (79\%) of 214 patients receiving high-dose therapy and $142(68 \%)$ of 205 patients on low-dose therapy had CR or PR within 4 cycles. ${ }^{90}$ However, the high response rates did not result in superior time to progression, PFS, or OS compared with low-dose dexamethasone. The trial was stopped after 1 year. Patients on high-dose therapy were allowed to cross over to the low-dose arm, since the OS rate was significantly higher in that arm. At 1-year interim analysis, OS was 96\% in the low-dose dexamethasone group compared with $87 \%$ in the high-dose group $(P=.0002)$; 2-year OS was $87 \%$ versus $75 \%$, respectively.

The cause of inferior OS with high-dose dexamethasone seems to be related to increased deaths caused by toxicity. Fifty-two percent of patients on the high-dose regimen compared with $35 \%$ on the low-dose regimen had grade 3 or worse toxic effects in the first 4 months, including DVT (26\% vs $12 \%$ ); infections including pneumonia (16\% vs $9 \%$ ); and fatigue ( $15 \%$ vs $9 \%)$. The 3 -year OS of patients who received 4 cycles of primary treatment with either dose followed by autologous SCT was 92\%, suggesting that lenalidomide and dexamethasone is a reasonable choice for primary therapy before SCT. However, it should be noted that the choice to proceed to SCT was not randomized but based on physician and patient preference.

A retrospective analysis of 411 newly diagnosed patients treated with either the lenalidomide and dexamethasone regimen $(n=228)$ or the thalidomide and dexamethasone regimen $(\mathrm{n}=183)$ was performed at the Mayo Clinic. ${ }^{91}$ In a matched-pair analysis, the differences between the 2 arms were similar for age, sex, transplantation status, and dexamethasone dose. The proportion of patients experiencing at least a PR to lenalidomide and dexamethasone was $80.3 \%$ versus $61.2 \%$ with thalidomide/dexamethasone; VGPR rates were $34.2 \%$ and $12.0 \%$, respectively. Patients receiving lenalidomide and dexamethasone had longer time to progression (median, 27.4 vs 17.2 months; $P=.019$ ), longer PFS (median, 26.7 vs 17.1 months; $P=.036$ ), and better OS (median not reached vs 57.2 months; $P=.018) .{ }^{91}$ Grade 3 or 4 adverse events $(57.5 \%$ vs $54.6 \%, P=.568$ ) were seen in a similar proportion of patients in both groups. Grade 3 or 4 toxicities of lenalidomide and dexamethasone were hematologic, mainly neutropenia $(14.6 \%$ vs $0.6 \% ; P<.001)$; the most common toxicities in thalidomide and dexamethasone were venous thromboembolism (VTE) (15.3\% vs 9.2\%; $P=.058)$ and peripheral neuropathy $(10.4 \%$ vs $0.9 \% ; P<.001)$. Based on the results of this meta-analysis, lenalidomide and dexamethasone seems well-tolerated and more effective than thalidomide and dexamethasone. ${ }^{91}$ However, randomized prospective trials are needed to confirm these results.

The incidence of DVT is low with single-agent lenalidomide or lenalidomide plus low-dose dexamethasone, but risk rises when combined with highdose dexamethasone. According to a recent report, patients treated with lenalidomide and high-dose dexamethasone who developed a VTE did not experience shorter OS or time to progression..$^{92}$ Prophylactic anticoagulation is recommended in patients receiving this therapy. ${ }^{75,93}$

A decrease in CD34-positive cells collected after prolonged lenalidomide treatment has been reported. ${ }^{94,95}$ Guidelines by the IMWG suggest that patients treated with lenalidomide and dexamethasone should have stem cells collected within the first 4 cycles of therapy. ${ }^{96}$ This inability to collect stem cells may be overcome by chemomobilization. ${ }^{97}$ There are data indicating successful stem cell harvest with the addition of plerixafor when conventional mobilization methods fail. 98,99

The NCCN Multiple Myeloma Panel recommends harvesting peripheral blood early in the course of primary treatment with lenalidomide. Lenalidomide and dexamethasone is listed as a category 1 primary treatment option in the NCCN Guidelines. The panel recommends appropriate thromboprophylaxis for patients receiving this therapy.

Bortezomib/Lenalidomide/Dexamethasone: Phase I/II study results have shown that primary therapy with bortezomib, lenalidomide, and dexamethasone 
is active and well tolerated in patients with newly diagnosed MM. ${ }^{100}$ Response rate is $100 \%$ with $74 \%$ VGPR or better and 52\% CR/near CR. Given this high extent and frequency of response, a randomized trial is now evaluating this regimen with or without high-dose melphalan and stem cell support in newly diagnosed transplant candidates.

The benefits of bortezomib, lenalidomide, and dexamethasone as primary therapy were also seen in the results of the phase II IFM 2008 trial $^{101}$ and phase II EVOLUTION trial. ${ }^{85}$ In the phase II IFM 2008 trial, patients received bortezomib, lenalidomide, and dexamethasone as induction therapy followed by stem cell transplantation. Patients subsequently received 2 cycles of bortezomib, lenalidomide, and dexamethasone as consolidation cycles and 1-year lenalidomide maintenance. VGPR rate or better at the completion of induction was $58 \%$. After transplantation and consolidation therapy, the rates of VGPR or better were $70 \%$ and $87 \%$, respectively. The phase II EVOLUTION trial was designed to examine the tolerability and efficacy of combining bortezomib, cyclophosphamide, lenalidomide, and dexamethasone versus bortezomib, lenalidomide, and dexamethasone versus cyclophosphamide, bortezomib, and dexamethasone in a randomized multicenter setting. The ORR after primary treatment followed by maintenance with bortezomib for 46 -week cycles was $85 \%(51 \% \geq \mathrm{VGPR}$ and $24 \% \mathrm{CR})$ with 1 -year PFS of $83 \%$ for the bortezomib, lenalidomide, and dexamethasone arm. ${ }^{85}$

The NCCN Panel included the bortezomib, lenalidomide, and dexamethasone regimen as a category $2 \mathrm{~A}$ option for primary treatment of transplanteligible patients with MM.

\section{Other Primary Therapy Regimens for Transplant Candidates}

Thalidomide/Dexamethasone: Rajkumar et $\mathrm{al}^{102}$ reported the results of a study involving 207 patients with newly diagnosed MM randomized to receive thalidomide and dexamethasone or dexamethasone alone. ${ }^{102}$ The response rate to the combined therapy was significantly higher compared with those receiving dexamethasone alone ( $63 \%$ vs $41 \%$, respectively). Stem cells for subsequent transplant were also successfully collected. However, increased toxicity is associated with thalidomide, specifically DVT; therefore, prophylactic anticoagulation is recommended if thalidomide and dexamethasone are given. ${ }^{93}$ Other side effects of thalidomide included rash, gastrointestinal disturbance, peripheral neuropathy, or somnolence. ${ }^{75}$ The use of thalidomide requires individual patient consideration, and the higher response rate of the thalidomide and dexamethasone combination must be weighed against the increased side effects.

Thalidomide in combination with dexamethasone as a primary regimen is a category $2 \mathrm{~B}$ recommendation in the NCCN Guidelines. The panel recommends appropriate thromboprophylaxis for patients receiving this therapy.

Single-Agent Dexamethasone: Dexamethasone alone may be an option as short-term primary therapy for a highly selected group of patients (eg, those with renal failure, hypercalcemia, cord compromise requiring radiation therapy, cytopenia). Single-agent dexamethasone as primary treatment is a category $2 \mathrm{~B}$ recommendation in the NCCN Guidelines.

\section{Liposomal Doxorubicin/Vincristine/Dexametha-} sone: In a noninferiority trial, newly diagnosed patients with active MM ( $n=192)$ were randomized to receive pegylated liposomal doxorubicin (PLD), vincristine, and dexamethasone regimen (DVD) or VAD regimen. ${ }^{103}$ The primary endpoints were response and toxicity. Objective response, PFS, and OS were similar between the treatment groups. However, pegylated DVD was associated with less toxicity compared with VAD. ${ }^{103}$ Data from this and other recent studies suggest that VAD should no longer be recommended, as most patients respond to an induction regimen based on novel drug combinations.

The DVD regimen is listed as a category $2 \mathrm{~B} \mathrm{rec-}$ ommendation for primary treatment in the NCCN Guidelines.

Carfilzomib/Lenalidomide/Dexamethasone: Carfilzomib is a second-generation proteosome inhibitor that binds highly selectively and irreversibly to the proteasome. It is administered intravenously. Preclinical studies with carfilzomib show lack of neurodegeneration in vitro ${ }^{104}$ and less neurotoxicity in animal studies. ${ }^{105}$ Carfilzomib has shown antimyeloma activity in patients with relapsed and/or refractory MM with an acceptable tolerability profile, including limited neuropathy after prolonged treatment. ${ }^{106-108}$

The safety and efficacy of carfilzomib in combination with lenalidomide and dexamethasone, as primary therapy for patients with MM, were evalu- 
Multiple Myeloma, Version 2.2016

ated in 2 single-arm trials. First, a multicenter phase I/II trial evaluated the combination of carfilzomib, lenalidomide, and dexamethasone in patients with newly diagnosed MM. ${ }^{109}$ In this trial, patients $(n=53)$ received carfilzomib $\left(20,27\right.$, or $36 \mathrm{mg} / \mathrm{m}^{2}$ on days 1 , $2,8,9,15$, and 16 and days 1, 2, 15, 16 after cycle 8) with lenalidomide $25 \mathrm{mg} /$ day on days 1 to 21 and dexamethasone $40 \mathrm{mg}$ weekly for cycles 1 to 4 then $20 \mathrm{mg}$ weekly for cycles 5 to 8 in 28-day cycles. After 8 cycles, patients received the regimen every other week (days $1,2,15$, and 16 of 28-day cycles) for 8 cycles. After 24 cycles of therapy, maintenance with single-agent lenalidomide was recommended off study. After a median of 12 cycles, $62 \%$ experienced at least a near-CR and $42 \%$ experienced an sCR. In 36 patients who completed 8 or more cycles, $78 \%$ achieved at least a near CR and $61 \%$ achieved a sCR. With median follow-up of 13 months, 24-month PFS was estimated at $92 \%$. The most common grade 3 and 4 toxicities in $10 \%$ or more of patients included hypophosphatemia (25\%), hyperglycemia (23\%), anemia (21\%), thrombocytopenia (17\%), and neutropenia (17\%). Peripheral neuropathy was limited to grade $1 / 2(23 \%) .{ }^{109}$ An updated follow-up analyses of the subset of 23 elderly patients (age $\geq 65$ years) showed that use of the carfilzomib, lenalidomide, and low dose dexamethasone regimen for an extended time resulted in deep and durable responses. All patients achieved at least a PR and with a median follow-up of 30.5 months, the PFS rate reported was $79.6 \%$ (95\%CI, 53.5-92.0) and OS was100\%. ${ }^{110}$

The second phase II trial also evaluated the same regimen (carfilzomib in combination with lenalidomide and dexamethasone) in patients $(n=45)$ with newly diagnosed MM. The dosing in this study was carfilzomib 20 or $36 \mathrm{mg} / \mathrm{m}^{2}\left(20 \mathrm{mg} / \mathrm{m}^{2}\right.$ on days 1 and 2 of cycle 1 only) on days $1,2,8,9,15$, and 16 , with lenalidomide $25 \mathrm{mg} /$ day on days 1 to 21 and dexamethasone $20 \mathrm{mg}$ on days $12,8,9,15,16,22$, and 23 for cycles 1 to 4 , then decreased to $10 \mathrm{mg}$ for cycles 5 to 8 (28-day cycles). After 8 cycles of treatment, patients with stable disease received up to 24 cycles of lenalidomide $10 \mathrm{mg} /$ day on days 1 to $21 .{ }^{111}$ Thirty-eight patients are evaluable for response and toxicity. After median follow-up of 10 months, PFS was $83.3 \%$. Twenty-five patients completed 8 cycles of the carfilzomib, lenalidomide, and dexamethasone regimen, of which 24 continued to lenalidomide therapy and 1 patient opted to exit the study after initial therapy. The most common nonhematologic and hematologic toxicities ( $\geq$ grade 3 ) in more than $10 \%$ of patients included electrolyte disturbances (18\%), liver function tests elevation (13\%), rash/ pruritus $(11 \%)$, fatigue (11\%), lymphopenia (63\%), anemia (16\%), leukopenia (13\%), and thrombocytopenia $(11 \%) .{ }^{112}$

Based on these data, the NCCN Panel has included the carfilzomib, lenalidomide, and dexamethasone regimen as a category $2 \mathrm{~A}$ option for primary treatment of transplant-eligible patients with MM.

\section{Preferred Primary Therapy Regimens for Non- transplant Candidates}

Many of the regimens described previously for transplant candidates are also options for non-transplant candidates. The regimens containing melphalan compromise stem cell reserve, and thus are options only for non-transplant candidates.

Melphalan/Prednisone/Thalidomide: Melphalan and prednisone (MP) has been a standard treatment of MM since 1960. A review of the clinical trials reported that MP results in a $60 \%$ response rate with duration of 18 months and an OS of 24 to 36 months. ${ }^{113}$ Palumbo et $\mathrm{al}^{114}$ were the first to report that when thalidomide was combined with melphalan and prednisone (MPT), combined near-CR and CR rates were $27.9 \%$ for MPT compared with $7.2 \%$ for MP. In the updated analysis, after a median follow-up of 38.1 months, the median PFS was 21.8 months for MPT and 14.5 months for MP $(P=.004)$. The median OS was 45.0 months for MPT and 47.6 months for $\operatorname{MP}(P=.79) .{ }^{115}$

Subsequently, several phase III trials have reported significantly higher ORR with MPT versus MP (57\%-76\% vs 31\%-48\%); including a higher CR or VGPR rate $(7 \%-15.5 \%) .{ }^{115-118}$ The impact of MPT on survival is not clear, as only the IFM studies $^{116,117}$ have reported a survival advantage for patients on MPT.

The phase III IFM 01-01 study compared the standard MP versus MPT in 232 newly diagnosed elderly (age $\geq 75$ years) patients with MM. ${ }^{117}$ After a median follow-up time of 47.5 months, median OS was significantly prolonged in the MPT group (44.0 months; 95\% CI, 33.4-58.7) compared with the MP group (29.1 months; 95\% CI, 26.4-34.9; HR, 0.68 in favor of MPT; $P=.028)$. Median PFS was significantly longer in the MPT group versus MP (24.1 months; 
95\% CI, 19.4-29.0 vs 18.5 months; 95\% CI,14.621.3; HR, 0.62 in favor of MPT; $P=.001) .{ }^{117}$

The phase III study by the HOVON group compared the standard MP versus MPT in 333 newly diagnosed elderly patients with MM. ${ }^{118}$ Significantly higher response rates were seen with MPT compared with MP and were comparable with response rates seen in the French and Italian trials described previously. With MPT, the ORR (CR+VGPR+PR) was $66 \%$ versus $45 \%$ with MP. The percentages of patients whose disease did not respond to therapy or with PD were 55\% with MP and 34\% with MPT. The EFS was 13 months with MPT versus 9 months with MP, and OS was 40 months with MPT versus 31 months with MP. ${ }^{118}$ Comparisons between these studies are difficult because of differences in patient populations, duration of treatment, and use of maintenance regimens.

A meta-analysis has demonstrated that in previously untreated, transplant-ineligible, elderly patients with MM, MPT results in significantly improved response rates and PFS with a trend towards improvement in OS compared with MP alone. ${ }^{119}$

Based on the significantly higher ORR consistently seen in all these studies, the NCCN Panel has included MPT as a category 1 primary treatment in transplant-ineligible patients with MM. The panel cautions that there is a significant risk of DVT with thalidomidebased therapy; therefore, use of thromboprophylaxis in patients on MPT therapy is highly recommended.

Melphalan/Prednisone/Lenalidomide: Melphalan and prednisone in combination with lenalidomide (MPL) was initially studied in 54 patients with newly diagnosed MM. ${ }^{120}$ Although there were concerns about myelosuppression with lenalidomide, therapy with oral MPL produced high response rates. Eightyone percent of patients experienced at least a PR, $47.6 \%$ experienced a VGPR, and 24\% experienced a CR (immunofixationnegative). One-year EFS in all patients was $92 \%$ and OS was $100 \%$. Common grade $3 / 4$ toxicities seen in patients were neutropenia (52\%), thrombocytopenia (24\%), and anemia $(5 \%)$. In another phase I/II trial of newly diagnosed patients with MM not eligible for autologous SCT (median age 74 years), MPL regimen showed substantial activity (CR was 12\%, ORR was $69 \%$ ) with a manageable toxicity profile. ${ }^{121}$ The most common grade $3 / 4$ toxicities were neutropenia $(58 \%$ of pa- tients) and thrombocytopenia (27\%). ${ }^{121}$

A subsequent phase III, multicenter, randomized, double-blind, placebo-controlled trial (MM-015), compared MPL induction followed by lenalidomide maintenance with MPL or MP followed by placebo in patients 65 years of age or older with newly diagnosed MM. ${ }^{122}$ The primary endpoint of the trial was PFS. A total of 459 patients were randomly assigned to receive MPL induction followed by lenalidomide maintenance (152 patients), MPL (153 patients), or MP (154 patients). MPL as an induction regimen had higher speed of response, ORR, and response quality compared with MP. For patients in the study of age 65 to 75 years, MPL provided a significant PFS benefit (HR, 0.62; P=.006). MPL did not improve PFS as compared with MP in patients older than 75 years of age. ${ }^{122}$

In the recently reported randomized, multicenter, phase III trial (E1A06) MPT was compared with MPL as primary treatment in newly diagnosed, non-transplant patients $(\mathrm{n}=306)$ with MM. The median age of patients was 75.7 years, and patients were followed for a median of 40.7 months. The study found no significant difference between the response rates, PFS, and OS in the two arms. ${ }^{123}$ However, several differences with respect to toxicity were found. Patients in the MPT arm had significantly more grade 3 or higher overall toxicity ( $73 \%$ vs $58 \%$; $P=.007)$ and grade 3 or higher non-hematologic toxicity ( $59 \%$ vs $40 \% ; P=.001)$ compared with patients in the MPL arm.

The MPL regimen is a category 1 primary treatment option for patients ineligible for transplant in the NCCN Guidelines for Multiple Myeloma.

Melphalan/Prednisone/Bortezomib: The addition of bortezomib to MP (MPB) was investigated in a large, randomized, international phase III VISTA (Velcade as Initial Standard Therapy in Multiple Myeloma) trial. ${ }^{124}$ The trial evaluated MP ( $\left.n=338\right)$ versus MPB $(n=344)$ in previously untreated patients with MM who were 65 years of age or older, or patients who were younger than 65 years of age and transplant ineligible. The regimen was well tolerated. The addition of bortezomib resulted in high rates of CR and significant prolongation of time to disease progression, PFS, OS, and time to next treatment. Importantly, adverse cytogenetics, advanced age, and renal function had no impact on the efficacy of the bortezomib-containing regimen. 
The final analysis of the phase III VISTA trial with median follow-up of 60.1 months (range, 0-74 months), showed a $31 \%$ reduced risk of death with MPB versus MP (HR, 0.695; P<.001). ${ }^{125}$ Reported median OS was 56.4 months with MPB versus 43.1 months with MP, with 5-year OS rates of $46.0 \%$ with MPB versus $34.4 \%$ with MP. ${ }^{125}$ No OS benefit was seen with the use of bortezomib among the small subgroup of patients with documented high-risk cytogenetics. Another interesting finding from this study was that patients relapsing after bortezomibbased therapy were not resistant to subsequent therapies and could be successfully treated with immunomodulatory drugbased therapies. Among patients who received subsequent therapies, survival from start of subsequent therapy was similar after treatment with MPB (median, 28.1 months) or MP (median, 26.8 months; HR, 0.914). These findings support the strategy of using bortezomibbased treatment as firstline therapy instead of reserving it for as therapy for relapsed/refractory disease. In addition, no increased risk of second primary malignancies was observed with MPB versus MP. ${ }^{125}$ The incidence of hematologic malignancies and solid tumors was similar in both arms, and was consistent with background incidence rate of for all cancers in the general US population of similar age group. ${ }^{125}$

There is no randomized head-to-head study comparing MPT and MPB; however, a meta-analysis of the phase III studies has demonstrated that better response rates could be expected with MPB than with MPT. ${ }^{126}$ Existing data on MP, MPT, and MPB were compared, and analysis showed $81 \%$ probability that MPB was the most efficacious among the 3 regimens in terms of ORR, with a greater than $99 \%$ probability that it was also the most efficacious in terms of CR. ${ }^{126}$

Advantages of MPB over MPT for transplantineligible patients include more rapid response and higher rates of $\mathrm{CR}$, with improved survival. ${ }^{127} \mathrm{No}$ difference was seen in OS and PFS between MPB and MPT regimens. Based on the VISTA trial results, the MPB regimen is now a NCCN category 1 primary treatment option for transplant-ineligible patients with MM.

Lenalidomide/Lowdose Dexamethasone: The results of the SWOG SO232 trial $^{88}$ that included transplant-ineligible patients and the ECOG E4A03 trial $^{128}$ that included elderly patients with MM demonstrate that lenalidomide in combination with lowdose dexamethasone is a well-tolerated and effective regimen for these groups of patients. In the ECOG E4A03 trial the OS rate was significantly higher in the lenalidomide plus low-dose dexamethasone arm compared with the lenalidomide plus high-dose dexamethasone arm (also discussed under "Preferred Primary Therapy Regimens for Transplant Candidates" page 1413). 90 The inferior survival outcome seen with high-dose dexamethasone was greatest in patients 65 years and older. At 2 years, patients who did not proceed to transplant had an OS rate of $91 \%$ with lenalidomide and low-dose dexamethasone..$^{90}$

The international, multicenter trial (FIRST trial) evaluated efficacy and safety of lenalidomide/ dexamethasone given continuously or for 72 weeks with MPT in elderly $(n=1623)$ transplantation-ineligible patients with newly diagnosed MM. ${ }^{129}$ The primary endpoint of this trial was PFS, and secondary endpoints were OS and adverse events, including the incidence of secondary malignancies. After a median of 37 months of follow-up, the risk of progression or death was reduced by $28 \%$ in patients receiving continuous lenalidomide/dexamethasone versus MPT (HR, 0.72; 95\% CI, 0.61-0.85, P<.001). ${ }^{129}$ Continuous lenalidomide/dexamethasone also reduced the risk of progression or death compared with 18 cycles of lenalidomide/dexamethasone (HR, 0.70; 95\% CI, $0.89-1.20 ; P=.70)$. In the interim analysis, an OS benefit was seen in the lenalidomide/dexamethasone arm versus MPT (HR: 0.78; CI, 0.64-0.96, P=.02). ${ }^{129}$

There are several reports showing higher incidences of secondary malignancies when lenalidomide is used as a maintenance therapy post-transplantation or in a melphalan-containing regimen. ${ }^{130-133}$ In the FIRST trial, the overall incidence of secondary malignancies, including hematologic malignancies, was lower in the continuous lenalidomide/dexamethasone arm. The overall rates of second primary cancers were $3.0 \%$ in the continuous lenalidomide/ dexamethasone arm, $6.0 \%$ in the arm receiving 18 cycles of lenalidomide/dexamethasone, and $5.0 \%$ in the MPT arm. ${ }^{129}$

Lenalidomide in combination with low-dose dexamethasone is considered a category 1 option by the NCCN Multiple Myeloma Panel for transplantineligible patients with MM. The panel recommends appropriate thromboprophylaxis for patients receiving this therapy.

Based on the results of the FIRST trial, the NCCN Panel recommends considering treatment 
with continuous lenalidomide/dexamethasone until disease progression for patients who are not eligible for transplant.

Bortezomib/Dexamethasone: A US communitybased, randomized, open-label, multicenter phase IIIb UPFRONT trial compared safety and efficacy of 3 highly active bortezomib-based regimens in previously untreated elderly patients with MM ineligible for SCT. ${ }^{134}$ The patients with symptomatic, measurable MM were randomized (1:1:1) to one of the following regimens: bortezomib and dexamethasone $(n=168)$; bortezomib, thalidomide, and dexamethasone $(n=167)$; or MPB $(n=167)$ followed by maintenance therapy with bortezomib. The primary endpoint was PFS; secondary endpoints included ORR, CR/near-CR and VGPR rates, OS, and safety. All 3 induction regimens exhibited substantial activity, with ORR of $73 \%$ (bortezomib and dexamethasone), 80\% (bortezomib, thalidomide, and dexamethasone), and 69\% (MPB) during the treatment period. ${ }^{134}$ After a median follow-up of 21.8 months, no significant difference in PFS was observed between the treatment arms. ${ }^{134}$ Response rates, including CR and VGPR or better, improved after bortezomib maintenance, with no concomitant increase in the incidence of peripheral neuropathy. The NCCN Multiple Myeloma Panel has included bortezomib and dexamethasone as a category $2 \mathrm{~A}$ primary therapy option for patients with MM who are ineligible for transplant.

Bortezomib/Lenalidomide/Dexamethasone: Phase II study results have shown that primary therapy with bortezomib, lenalidomide, and dexamethasone is active and well tolerated in all newly diagnosed patients with MM regardless of autologous SCT status. ${ }^{100}$ A post-hoc analysis of the study showed a low risk of progression after 1 year of initiation of therapy regardless of ASCT status. The18-month PFS rate of $75 \%$ and OS rate of $97 \%$ after lenalidomide, bortezomib, dexamethasone with or without autologous SCT. The NCCN Panel included the bortezomib, lenalidomide, and dexamethasone regimen as a category 2A option for patients with MM not eligible for SCT.

Cyclophosphamide/Bortezomib/Dexamethasone: The role of CyBorD as initial therapy for patients with MM ineligible for transplant was studied in a small phase II trial $(n=20)$. The median age of pa- tients in this study was 76 years (range 66-90). At a median follow-up of 9.5 months, the OS was $100 \%$ and at median of 12 month, and 5 had disease progression. With respect to toxicity, 6 patients experienced nonhematological grade 3/4 adverse events (20\%), including muscle weakness, sepsis, and pneumonia. Neutropenia and thrombocytopenia were seen in 2 patients (10\%). ${ }^{135}$ Based on the above and the results from the EVOLUTION trial (described earlier) that did not exclude transplant ineligible patients, the NCCN panel has included CyBorD as a primary therapy option (category 2A) for nontransplant candidates.

\section{Other Primary Therapy Regimens for Non- transplant Candidates}

Both MPT and MPB regimens have reported superior responses compared to MP. However, MP may still have a role in patients who do not have access to novel agents. According to the NCCN Multiple Myeloma Panel, MP is a category 2A recommendation. The other NCCN category 2B options for patients not eligible for SCT include thalidomide and dexamethasone, single-agent dexamethasone, DVD, and VAD.

\section{Follow-up of Transplant and Non-transplant Candidates After Primary Therapy}

Patients on treatment should be monitored for response to therapy, for response to primary therapy, and for symptoms related to disease and/or treatment. It is recommended to reevaluate (after 2 cycles) with the laboratory tests, bone survey, and bone marrow aspiration and biopsy to determine treatment response, or whether the primary disease is progressive. Potential transplant candidates must undergo a stem cell harvest, collecting enough stem cells for two transplants in anticipation of a tandem transplant or a second transplant as subsequent therapy. Alternatively, all patients may consider continuation of primary therapy till the best response is reached. The optimal duration of primary therapy after achieving maximal response is unknown; hence, maintenance therapy (see "Maintenance Therapy," page 1425) or observation can be considered beyond maximal response.

Follow-up tests include those used for initial diagnosis: a CBC with differential and platelet counts; BUN; serum creatinine and corrected serum calcium; and quantification of M-protein and immunoglobulins. The serum FLCs may be assessed as clinically 
indicated (especially in patients with oligo- or nonsecretory MM). According to the NCCN Panel, response should be assessed using the IMWG criteria. $^{9}$

\section{Stem Cell Transplants}

\section{Introduction}

High-dose therapy with stem cell support is a critical component in the treatment plan for eligible, newly diagnosed patients with MM. The types of SCT may be single autologous SCT, a tandem SCT (a planned second course of high-dose therapy and SCT within 6 months of the first course), or an allogeneic SCT. An allogeneic SCT can be performed after prior myeloablative therapy or after nonmyeloablative therapy. Nonmyeloablative therapy, also referred to as "mini transplant," has been investigated as a technique to decrease toxicity of the allotransplant while preserving the alloimmune graftversusmyeloma effect. ${ }^{136,137}$ An allogeneic SCT may also follow an autologous SCT.

The NCCN Guidelines for Multiple Myeloma indicate that all types of SCT are appropriate in different clinical settings; these indications are discussed further below. In general, all candidates for highdose chemotherapy must have sufficient liver, renal, pulmonary, and cardiac function. However, renal dysfunction is not absolute contraindication to transplant. Earlier studies of autologous transplant included total body irradiation $(\mathrm{TBI})$ as a component of the preparative regimen. Regimens with chemotherapy have only recently been shown to have equivalent efficacy and less toxicity than TBI. TBI regimens have now been abandoned, ${ }^{138}$ but newer, potentially less toxic radiation techniques aimed to deliver total marrow irradiation while reducing toxicities to nontarget organs are currently undergoing evaluation in clinical trials. ${ }^{139}$

\section{Autologous Stem Cell Transplants}

Autologous SCT results in high response rates and remains the standard of care after primary therapy for eligible patients. In 1996, results of the first randomized trial were reported; this trial demonstrated that autologous SCT is associated with statistically significant higher response rates and increased OS and EFS when compared with the response of similar patients treated with conventional therapy. ${ }^{140}$ In 2003, results of a second trial comparing highdose therapy to standard therapy showed an increase in the CR rate and an improvement in OS (54 months in the highdose group compared to 42 months for standard therapy). ${ }^{141}$ The benefit was more pronounced for higher-risk patients. Barlogieet a ${ }^{142}$ reported on the results of an American trial that randomized $510 \mathrm{pa}-$ tients to receive high-dose therapy with autologous stem cell support or standard therapy. With a median follow-up of 76 months, there were no differences in response rates, PFS, or OS between the two groups. The reason for the discrepant results are not clear, but may be related to differences in the specific highdose and conventional regimens between the American and French study. For example, the American study included TBI as part of the high-dose regimen; TBI has subsequently been found to be inferior to high-dose melphalan. ${ }^{138}$

Another trial included 190 patients 55 to 65 years of age randomized to standard or high-dose therapy. ${ }^{143}$ This study was specifically designed to include older patients, since the median age of the participants in other trials ranged from 54 to 57 years whereas the median age in this trial was 61 years. After 120 months of follow-up, there was no significant difference in OS, although there was a trend toward improved EFS in the high-dose group $(P=.7)$. Additionally, the period of time without symptoms, treatment, or treatment toxicity (TWiSTT) was significantly longer in the high-dose group. The study concluded that the equivalent survival suggests that the treatment choice between high-dose and conventional-dose chemotherapy should be based on personal choice in older patients. For example, an early transplant may be favored because patients can enjoy a longer interval of symptom-free time. However, this study ${ }^{144}$ also showed that a transplant performed at relapse has a similar OS compared to an early transplant. The choice of early versus late transplant was examined in a randomized French tri$\mathrm{al}$, and the results in both arms are comparable with respect to OS. ${ }^{145}$ However, early SCT was superior in terms of quality of life, assessed as time without symptoms and side effects from therapy. ${ }^{145}$

It should be noted that all randomized studies of autologous SCT after primary therapy were designed and implemented before the availability of thalidomide, lenalidomide, or bortezomib. Therefore, the role of transplant may evolve in the future. The results of the PETHEMA trial strongly support the use of upfront autologous SCT for MM even in 
the era of novel agents. ${ }^{82}$ The response rates were evaluated after induction therapy and after autologous SCT. Taking into consideration patients who actually underwent the autologous SCT, the CR rates were increased from $35 \%$ pre-transplant to $57 \%$ post-transplant, in the group treated with bortezomib, thalidomide, and dexamethasone as induction therapy and from $14 \%$ to $40 \%$ in the group treated with thalidomide and dexamethasone as induction therapy. ${ }^{82}$

A recent phase III study compared high-dose melphalan followed by autologous SCT with MPL. Patients $(n=402)$ were randomly assigned (in a $1: 1: 1: 1$ ratio) to one of the four groups: high-dose therapy and SCT followed by maintenance with lenalidomide; high-dose therapy and SCT alone; primary therapy with MPL followed by lenalidomide; and primary therapy with lenalidomide alone. The primary study endpoint was PFS. Secondary endpoints included OS, the ORR, the time to a response, and safety. ${ }^{146}$ The comparison of the group treated with high-dose melphalan therapy followed by stem-cell transplantation with MPL shows that high-dose melphalan therapy followed by stem-cell transplantation was associated with a significant reduction in the risk of progression or death (HR, 0.44) and prolonged OS (HR for death, 0.55). ${ }^{147}$

Results from the IFM 2005/01 study of patients with symptomatic myeloma receiving primary therapy with either bortezomib and dexamethasone versus VAD showed a marked improvement in ORR with bortezomib and dexamethasone over VAD (discussed under section titled "Preferred Primary Therapy Regimens for Transplant Candidates," page 1413). ${ }^{76}$ Responses were evaluated after primary treatment and postautologous SCT. After the first autologous SCT, CR/near-CR rates were $35.0 \%$ in the bortezomib plus dexamethasone arm, compared with $18.4 \%$ in the VAD arm. ${ }^{76}$ The VGPR rates were $54.3 \%$ versus $37.2 \%$. Median PFS was 36.0 months versus 29.7 months $(P=.064)$ with bortezomib plus dexamethasone versus VAD after a median followup of 32.2 months. ${ }^{76}$ Also, PFS was also significantly longer in the patients achieving greater than or equal to a VGPR after primary treatment than in patients achieving a less than VGPR (median 36 vs 29.7 months). ${ }^{76}$

In another study, 474 patients were randomized to primary therapy with bortezomib, dexametha- sone, and thalidomide $(\mathrm{n}=236)$ or thalidomide and dexamethasone $(n=238)$ before double autologous SCT.148 The 3-drug regimen yielded high response rates compared with the 2 -drug regimen, with a CR rate of $19 \%$ (vs $5 \%$ ) and $\geq$-VGPR of $62 \%$ (vs $31 \%$ ). After SCT, improved incremental responses were still seen with bortezomib/dexamethasone/thalidomide compared with thalidomide plus dexamethasone. Taken together, these studies suggest that improved responses with the primary regimen result in improved outcomes after transplantation.

Studies have found that PD emerging after primary therapy does not preclude a good response to autologous SCT..$^{142,149,150}$ For example, Kumaret al ${ }^{150}$ reported on a case series of 50 patients with primary progressive MM receiving an autologous SCT. Results were compared to 100 patients with responsive disease undergoing autologous SCT. The one-year PFS from the time of transplant was $70 \%$ in the primary progressive group compared to $83 \%$ in the chemosensitive group. For this reason, the NCCN Guidelines indicate autologous SCT as a category 1 option for treatment of primary progressive or refractory disease post primary treatment.

\section{Tandem Stem Cell Transplants}

Tandem SCT refers to a planned second course of high-dose therapy and SCT within 6 months of the first course. Planned tandem transplants have been studied in several randomized trials. The IFM94 trial reported by Attal et al randomized newly diagnosed patients with MM to single or tandem autologous transplants. ${ }^{151}$ A total of $78 \%$ of patients assigned to the tandem transplant group received the second transplant at a median time of 2.5 months after the first. The probability of surviving event-free for 7 years after the diagnosis was $10 \%$ in the single transplant group compared to $20 \%$ in the double transplant group. An accompanying editorial by Stadtmauer questions whether the promising results might be related to regimens used, rather than to the effect of two courses of high-dose therapy. ${ }^{152}$ For example, patients in the single transplant arm received $140 \mathrm{mg} / \mathrm{m}^{2}$ melphalan plus TBI, whereas those in the tandem arm received the same dose without TBI for the initial transplant and with TBI for the second transplant. As noted above, TBI has been shown to be more toxic without providing additional benefit. Based on this, the editorial suggests that the increased survival in the tandem arm of the IFM94 
Multiple Myeloma, Version 2.2016

trial may have resulted from greater cumulative exposure to melphalan ( $280 \mathrm{vs} 140 \mathrm{mg} / \mathrm{m}^{2}$ ). In a subset analysis, those patients who did not achieve a complete CR or a VGPR within 3 months after the first transplant appeared to benefit the most from a second transplant. The investigators of the IFM94 study have suggested that the improvement in projected survival associated with tandem transplant is related not to improved response rates, but to longer durations of response. Four other randomized trials have compared single versus tandem transplant. ${ }^{143,153-155}$ None of these trials showed a significant improvement in OS. However, since the median follow-up in these trials ranged from 42 to 53 months, the lack of significant improvement is not surprising. The trial by Cavo et $\mathrm{al}^{153}$ found that patients not in CR or near-CR after the first transplant benefited the most from a second transplant. This confirms the observations of the IFM94 trial using nonTBI-based highdose regimens.

In both the French and Italian trials, the benefit of a second autologous SCT was seen in patients who do not experience a CR or VGPR (greater than $90 \%$ reduction in $\mathrm{M}$-protein level) with the first procedure. These two studies were not adequately powered to evaluate the equivalence of one versus two transplants in patients achieving a CR or VGPR after the first transplantation.

A review of long-term outcomes of several trials of autologous transplantation by Barlogie et al found that tandem transplantations were superior to both single transplantations and standard therapies. ${ }^{156}$ Also, postrelapse survival was longer when EFS was sustained for at least 3.5 years after tandem transplantation. ${ }^{156}$ The NCCN Multiple Myeloma Panel recommends collecting enough stem cells for two transplants in all eligible patients. According to the NCCN Multiple Myeloma Panel, a tandem transplant with or without maintenance therapy can be considered for all patients who are candidates for SCT, and is an option for patients who do not achieve at least a VGPR after the first autologous SCT. The support for use of maintenance therapy after tandem transplant comes from the study by Palumbo et al $^{146}$ (discussed in the previous section) addressed the role of maintenance therapy with lenalidomide after autologous transplantation. ${ }^{146} \mathrm{Al}$ though associated with more frequent grade 3 or 4 neutropenia and infections, maintenance therapy with lenalidomide was found to significantly reduced risk of disease progression or death (HR, 0.47) after both single and tandem transplantation compared with no maintenance. ${ }^{146}$

The benefit from the second transplant in patients, who are in CR, or VGPR, and also in those who achieve less than VGPR after the first SCT, should preferably be answered in a clinical trial. In fact, such a randomized prospective NIH- and Intergroup-supported trial is currently ongoing. The other options for this group of patients include maintenance therapy or observation.

\section{Allogeneic Stem Cell Transplant}

Allogeneic SCT includes either myeloablative or nonmyeloablative (ie, "mini" transplant) transplants. Allogeneic SCT has been investigated as an alternative to autologous SCT both to avoid the contamination of reinfused autologous tumor cells, but also to take advantage of the beneficial graft-versustumor effect associated with allogeneic transplants. However, lack of a suitable donor and increased morbidity has limited this approach, particularly for the typical older MM population. Nonmyeloablative transplants are designed to decrease the morbidity of the high-dose chemotherapy but preserve the beneficial graft-versus-tumor effect. Therefore, the principal difference between myeloablative and nonmyeloablative transplants relates to the chemotherapy regimen used. Specific preparatory regimens have not been a focus of the NCCN Guidelines, and therefore these Guidelines do not make a distinction between these approaches.

Given the small candidate pool, it is not surprising that there have been no randomized clinical trials comparing myeloablative allogeneic to autologous SCT, but multiple case series have been published describing allogeneic SCT as an initial or as therapy for relapsed/refractory MM. In a 1999 review, Kyle reported a mortality rate of $25 \%$ within 100 days and overall transplant-related mortality of approximately $40 \%$ and few patients were cured. ${ }^{157}$ Other reviews have also reported increased morbidity without convincing proof of improved survival. ${ }^{149,158}$ However, there are intriguing data from the SWOG randomized trial of autologous transplant versus conventional chemotherapy. ${ }^{142}$ The original trial had an ablative, allogeneic transplant group consisting of patients with HLA identical siblings. Thirty-six patients received allografts, and due to 
the high 6 -month mortality of $45 \%$, the allogeneic arm was closed. With 7 years of follow-up, the OS of the conventional chemotherapy, autologous, and allogeneic arms were all identical at 39\%. The autologous and conventional chemotherapy arms do not demonstrate a plateau, whereas the allogenic curve was flat at $39 \%$. This suggests that a proportion of these patients are long-term survivors. Thus, there is ongoing interest in myeloablative allogeneic SCT, particularly given the lack of a significant cure rate for single or tandem autologous SCT.

The NCCN Guidelines consider myeloablative allogeneic SCT an accepted option, preferably in a clinical trial in: 1) patients whose disease responds to primary therapy; 2) patients with primary PD; or 3 ) patients with PD after an initial autologous SCT.

Another strategy that has been investigated is initial autologous SCT followed by a miniallogeneic transplant. A prospective trial by Bruno et $\mathrm{al}^{159}$ showed that, among patients ( $<65$ years) with HLA-matched siblings who received an autograftallograft regimen, CR rate after allografting was 55\%, compared with $26 \%$ after double autograft in patients without HLA-matched siblings. Median OS was higher ( 80 vs 54 months). In the prospective PETHEMA trial in patients who do not achieve at least near-CR with a first autologous SCT, there was no significant difference in OS after double autologous SCT versus autologous SCT followed by miniallogeneic transplant. However, a trend toward a longer PFS was observed in the group treated with autologous SCT followed by miniallogeneic transplant. ${ }^{160}$ In contrast, the IFM trial (9903) by Garban et al ${ }^{161}$ and the BMTCTN 0102 trial $^{162}$ reported no OS or PFS advantage with autologous transplant followed by allogeneic transplant in patients with high risk.

In a prospective study of patients with newly diagnosed MM, patients were selected for treatment with autologous SCT followed by reduced-intensity conditioning allogeneic SCT or autologous SCT based on the availability of an HLA-identical sibling. ${ }^{163}$ The induction chemotherapy in this study consisted of the chemotherapy that was standard at the time- the VAD or VAD-like regimen. After 60 months, the incidence of relapse/progression was $49 \%$ in the group treated with autologous SCT followed by reduced-intensity conditioning allogeneic SCT versus $78 \%$ in the autologous SCT group. AT 60 months, the OS and CR rates were $65 \%$ and $51 \%$, respectively, for patients treated with autologous SCT followed by reduced-intensity conditioning allogeneic SCT compared with 58\% and 41\% for those treated with autologous SCT. Based on these study results, patients who have an HLA-identical sibling may be considered candidates for reduced-intensity allogeneic SCT as part of their first-line treatment.

Patients whose disease either does not respond to or relapses after allogeneic stem cell grafting may receive donor lymphocyte infusions to stimulate a beneficial graft-versus-myeloma effect ${ }^{164-171}$ or other myeloma therapies on or off a clinical trial.

\section{Maintenance Therapy}

\section{Thalidomide as Maintenance Therapy After Autologous SCT}

Thalidomide as maintenance therapy after a prior autologous SCT has been studied in retrospective and independent randomized trials. In a retrospective review of 112 patients undergoing autologous SCT, Brinkeret $\mathrm{al}^{172}$ reported on the outcomes of 36 patients who received thalidomide as maintenance compared to 76 patients who received no post-transplant therapy. The median survival in the thalidomide group was 65.5 months compared to 44.5 months in the no treatment group $(P=.9)$. Attal et $\mathrm{al}^{173}$ randomized 597 patients to one of three different strategies after tandem autologous SCT: no maintenance, pamidronate alone, or pamidronate combined with thalidomide. There was a highly significant EFS and OS advantage in the thalidomide and pamidronate arm. The group that appeared to benefit the most was one that had patients who achieved only a PR after transplantation. In another randomized trial, thalidomide maintenance induced improvement in PFS in patients achieving less than a VGPR after autologous SCT with no survival benefit. ${ }^{174}$ Thalidomide has also been used before, during, and after tandem autologous SCT. ${ }^{142,175}$ In a randomized study of 668 newly diagnosed patients, half received thalidomide throughout the course of the tandem autologous SCT. Thalidomide was incorporated into primary therapy, continued between the tandem autologous SCT, and incorporated into consolidation therapy and continued as maintenance therapy. ${ }^{175}$ The group that was not treated with thalidomide received the same core therapy. After a median follow-up of 42 months, the group that received 
Multiple Myeloma, Version 2.2016

thalidomide had improved CR rates (62\% vs $43 \%$ ) and 5 -year EFS rates ( $56 \%$ vs $44 \%$ ). However, the OS rate was approximately $65 \%$ in both groups. $\mathrm{Pa}$ tients who did not receive thalidomide throughout therapy benefited from thalidomide therapy at relapse. The results of this study suggest that sequencing drugs may be important. For example, if thalidomide is used as part of primary therapy, another drug should be considered for maintenance therapy.

An Australian study compared thalidomide plus prednisone versus prednisone alone as maintenance therapies post autologous SCT. The results confirm that thalidomide added to maintenance is superior to prednisone alone. ${ }^{176} \mathrm{~A}$ recent analysis of the Canadian NCIC randomized study comparing thalidomide and prednisone with observation after autologous SCT showed that thalidomide and prednisone improves the duration of disease control, but is associated with lower patient-reported quality of life and no OS benefit. ${ }^{177}$

Based on the previously noted evidence, the NCCN Multiple Myeloma Panel has listed singleagent thalidomide as a category 1 option under "Preferred Maintenance Regimens." Thalidomide in combination with prednisone is included under "Other Maintenance Regimens" and is a category 2A. There are concerns about the cumulative toxicity with thalidomide. For example, peripheral neuropathy observed with thalidomide is related to the duration of treatment and is cumulative. The benefits and risks of maintenance therapy with thalidomide should be discussed with patients.

\section{Lenalidomide as Maintenance Therapy After Autologous SCT}

Lenalidomide as maintenance therapy after autologous transplantation has been evaluated in two independent randomized phase III studies. ${ }^{130,131}$ In The CALGB 100104 trial, patients were randomized to maintenance therapy with lenalidomide $(n=231)$ versus placebo $(n=229)$ after autologous SCT. ${ }^{131}$ At a median follow-up of 34 months, $37 \%$ of the patients who received lenalidomide versus $58 \%$ who received placebo had disease progression or died. The median time to progression in the lenalidomide group was 46 months versus 27 months in the placebo group $(P<.001)$. Second primary cancers occurred in 18 patients who received lenalidomide $(8 \%)$ and in 6 patients who received placebo (3\%). ${ }^{131}$

Data from the international, randomized, doubleblind phase III IFM 200502 trial $(n=614)$ show that patients treated with lenalidomide as consolidation therapy after an autologous SCT followed by lenalidomide as maintenance therapy had upgraded responses. Of the 614 patients enrolled in the trial, 307 were randomly assigned to lenalidomide maintenance therapy and 307 to placebo. Maintenance treatment was continued until the patient withdrew consent, the disease progressed, or unacceptable toxic effects occurred. The final analysis of the IFM 200502 trial was performed after a median follow-up of 30 months and 264 patients had disease progression (104 in the lenalidomide group and 160 in the placebo group). The median PFS was 41 months in the lenalidomide group, compared with 23 months in the placebo group (HR, 0.50; $P<.001 ;$ median follow-up period was 30 months). The probability of surviving without progression for 3 years after randomization was $59 \%$ in those treated with lenalidomide and $35 \%$ in those who received the placebo. The benefit of lenalidomide maintenance therapy, evidenced by rate of PFS at 3 years after randomization, was higher in all patients who received lenalidomide maintenance therapy, compared with those who received placebo. This benefit was observed in patients who had a VGPR at randomization $(64 \%$ vs $49 \%, \mathrm{P}=.006)$ and those who did not ( $51 \%$ vs $18 \%$, $\mathrm{P}<.001) .{ }^{130}$ An increased incidence of second primary cancers was observed in the lenalidomide group (32 had second primary cancers in the lenalidomide group and 12 in the placebo group). ${ }^{130}$

In a phase II study by the IFM group, lenalidomide maintenance was shown to upgrade responses seen in $27 \%$ of patients ( 8 of 31 patients) after induction therapy with lenalidomide, bortezomib, and dexamethasone followed by autologous transplant. ${ }^{101}$

The study by Palumbo et $\mathrm{al}^{146}$ (discussed in "Autologous Stem Cell Transplants," page 1422) showed that although maintenance therapy with lenalidomide is associated with more frequent grade 3 or 4 neutropenia and infections, it significantly reduced risk of disease progression or death $(\mathrm{HR}, 0.47)$ compared with no maintenance. ${ }^{146}$

A report from the HOVON 76 trial indicates that lenalidomide maintenance may not be a feasible option after miniallogeneic SCT. ${ }^{178}$ However, another recently reported study has shown the feasibility of maintenance therapy with low-dose lenalidomide after allogeneic SCT in patients with high-risk MM. ${ }^{179}$ 
Lenalidomide as Maintenance Therapy After Non-transplant Active Primary Treatment

Data from the phase III MM015 study show that lenalidomide maintenance after MPL primary therapy significantly reduced the risk of disease progression and also increased PFS. ${ }^{122}$ In this study, newly diagnosed patients with MM $(n=459)$ aged 65 or older years were randomized to receive MP followed by placebo, MPL, or MPL followed by lenalidomide until progression. Maintenance with lenalidomide significantly prolonged PFS. The PFS of patients treated with MPL followed by maintenance lenalidomide was significantly prolonged $(n=152$; median, 31 months) compared with the other two arms: MPL ( $n=153$; median, 14 months; HR, 0.49; $P<.001$ ) or MP ( $n=154$; median, 13 months; HR, 0.40; $P<.001$ ). Lenalidomide maintenance therapy improved PFS by $66 \%$ compared with placebo, regardless of age. ${ }^{122}$

Based on the evidence from the phase III trials, ${ }^{122,130,131}$ the NCCN Multiple Myeloma Panel lists single-agent lenalidomide as one of the preferred maintenance regimens (category 1). Lenalidomide lacks the neurologic toxicity seen with thalidomide. However, there seems to be an increased risk for secondary cancers, especially post-transplantation, ${ }^{130,131,180}$ or after a melphalan-containing regimen. ${ }^{133}$ According to the results of the FIRST trial, in the continuous lenalidomide/dexamethasone arm, the absence of the alkylator melphalan seems to be more effective in terms of improving PFS and lowering incidence of second malignancies. ${ }^{129}$

A metaanalysis of 4 randomized controlled trials examined patients treated with lenalidomide maintenance versus patients with no maintenance or placebo in both the transplant and non-transplant settings. ${ }^{181}$ The analysis showed that patients treated with lenalidomide maintenance had significantly improved PFS (HR, 0.49; $\mathrm{P}<.001)$ and a trend toward $\mathrm{OS}(\mathrm{HR}, 0.77 ; P=.071)$ versus no maintenance or placebo. ${ }^{181}$ There was significantly more grade $3 / 4$ neutropenia with the use of lenalidomide and a 2-fold increased risk of secondary malignancies.

The NCCN Panel notes that the benefits and risks of maintenance therapy with lenalidomide versus secondary cancers should be discussed with patients.

\section{Bortezomib as Maintenance Therapy after Autologous SCT}

The results from the HOVON study show that maintenance with single-agent bortezomib after autologous SCT is well tolerated and is associated with improvement of ORR. ${ }^{79}$ Patients in the $\mathrm{HO}$ VON trial were randomly assigned to one of the two arms consisting of either primary treatment with vincristine/doxorubicin/dexamethasone followed by autologous SCT and maintenance with thalidomide or with bortezomib/doxorubicin/dexamethasone followed by autologous SCT and bortezomib as maintenance therapy for 2 years. The study reported high near-CR/CR rates after primary treatment with the bortezomib-based regimen. Bortezomib as maintenance therapy was well tolerated and associated with additional improvement of response rates ${ }^{79}$ (see "Preferred Primary Therapy Regimens for Transplant Candidates," page 1413).

A multicenter phase III trial in newly diagnosed patients with MM showed that consolidation with bortezomib after autologous SCT, improved PFS only in patients not achieving at least VGPR after autologous SCT. ${ }^{182}$ There was no difference in PFS in patients with VGPR or better after autologous SCT.

\section{Bortezomib as Maintenance Therapy After Non- transplant Active Primary Treatment}

The preliminary results of the phase III UPFRONT study also show that maintenance with single-agent bortezomib is well-tolerated when administered after treatment with bortezomibbased primary therapy. ${ }^{183}$ Newly diagnosed patients with MM ineligible for high-dose therapy and SCT enrolled in the UPFRONT trial were randomized $(1: 1: 1)$ and treated with one of the following bortezomib-based primary regimens: bortezomib and dexamethasone; bortezomib in combination with thalidomide and dexamethasone; or bortezomib with melphalan and prednisone followed by maintenance treatment with bortezomib. The updated results show that the response rates, including CR and VGPR or better, improved after bortezomib maintenance in all arms, with no concomitant increase in the incidence of peripheral neuropathy. ${ }^{183}$ The NCCN Multiple Myeloma Panel Members have added bortezomib to the list of preferred maintenance regimens with a category $2 \mathrm{~A}$ designation.

\section{Other Maintenance Therapy Regimens}

Several other maintenance therapies, such as steroids (dexamethasone) and interferon, have been investigated in patients whose disease responds to high-dose therapy followed by autologous or alloge- 
neic SCT. ${ }^{184}$ At the present time, the role of interferon ${ }^{185}$ or steroid maintenance therapy ${ }^{186}$ in general is uncertain. Therefore, these are category $2 \mathrm{~B}$ recommendations as maintenance therapy in the NCCN Guidelines for Multiple Myeloma.

Patients enrolled in the PETHEMA trial were randomized to maintenance with thalidomide plus bortezomib, thalidomide, or alfa-2b-interferon after treatment with induction therapy and autologous SCT. ${ }^{187}$ Maintenance with bortezomib plus thalidomide increased the post-transplant CR rate by $21 \%$ compared with maintenance with either thalidomide or alfa- $2 \mathrm{~b}$ interferon, each of which increased the CR rate by $15 \%$. After a median follow-up of 34.9 months, PFS from start of maintenance was significantly longer with bortezomib plus thalidomide versus thalidomide or alfa-2b-interferon $(P=.0009)$; there was no significant difference in $\mathrm{OS}(P=.47)$ between the 3 arms. Rates of grade 3 and 4 thrombocytopenia were $10 \%$ with bortezomib plus thalidomide versus $2 \%$ with thalidomide $(P=.01)$. Rates of grade 3 peripheral neuropathy were $15 \%, 14 \%$, and $0 \%$ in the bortezomib plus thalidomide arm, thalidomide arm, and alfa-2b-interferon arm, respectively. ${ }^{187}$

Transplant-ineligible patients from the Spanish GEM2005MAS65 phase III trial were randomized to maintenance with bortezomib plus thalidomide or bortezomib plus prednisone after bortezomib-based primary therapy. ${ }^{188}$ After a median of 38 months from the start of maintenance the results reported that overall CR rate increased from $24 \%$ after primary therapy to $42 \%$ (the difference in CR between the two maintenance regimens was not significant for bortezomib plus thalidomide: $46 \%$; bortezomib plus prednisone: $39 \%) .{ }^{188}$

After a median follow-up of 46 months from initiation of primary therapy, median PFS among all patients receiving maintenance was 35 months (39 months in patients receiving bortezomib plus thalidomide and 32 months in patients receiving bortezomib plus prednisone; $P=.1$ ). The 5 -year median OS rate was $59 \%$ (69\% in those receiving bortezomib plus thalidomide, and $50 \%$ in those receiving bortezomib plus prednisone; $P=.1$ ). Rates of nonhematologic grade 3 and 4 adverse events with bortezomib and thalidomide versus bortezomib and prednisone were $17 \%$ versus 5\% (P=.009), including 9\% versus $3 \%$ grade 3 and 4 peripheral neuropathy. ${ }^{188}$

Based on the above data, the NCCN Multiple
Myeloma Panel Members have added bortezomib plus thalidomide and bortezomib plus prednisone as options for maintenance therapy (category 2B).

\section{Adjunctive Treatment for Multiple Myeloma}

Important advances have been made in adjunctive treatment/supportive care of patients with MM. This involves careful patient education about the probable side effects of each drug and the drug combinations being used, and the supportive care measures required. Supportive care can be categorized into those measures required for all patients and those that address specific drugs.

Bony manifestations of myeloma, in the form of diffuse osteopenia and/or osteolytic lesions, develop in $85 \%$ of patients. Related complications are the major cause of limitations in quality of life and performance status in patients with MM. A large, double-blind, randomized trial has shown that monthly use of intravenous pamidronate (a bisphosphonate) can decrease pain and bonerelated complications, improve performance status, and, importantly, preserve quality of life in patients with Durie-Salmon stage III MM and at least one lytic lesion. ${ }^{189,190}$ Zoledronic acid has equivalent benefits. ${ }^{191}$ Results from the study conducted by Zervas et $\mathrm{al}^{192}$ show a 9.5 -fold greater risk for the development of osteonecrosis of the jaw with zoledronic acid compared to pamidronate. Patients who are on bisphosphonates should have their renal function monitored. They should have a dental exam prior to start of bisphosphonate therapy and be monitored for osteonecrosis of the jaw.

The MRC Myeloma IX study examined effects of zoledronic acid versus clodronate (a bisphosphonate not currently FDA approved) in patients with MM initiating chemotherapy regardless of bone disease. The patients were randomized to receive zoledronic acid $(n=981)$ or clodronic acid $(n=979)$. Zoledronic acid was reported to reduce mortality and significantly improve PFS. ${ }^{193}$ Patients on clodronate and zoledronic acid had similar occurrence of acute renal failure and treatment-related serious adverse events. Zoledronic acid was associated with higher rates of confirmed osteonecrosis of the jaw than was clodronic acid. ${ }^{193-195}$ The study reanalyzed and recently reported survival outcomes. After an extended follow- 
up (median, 5.9 years), in addition to PFS, the OS was also significantly improved ( 52 vs 46 months; HR, 0.86; $P=.01$ ) compared with clodronic acid. ${ }^{196}$ The long-term rates of osteonecrosis of the jaw were also observed to be higher with zoledronic acid compared with clodronate $(3.7 \%$ vs $0.5 \% ; P=.0001) .{ }^{196}$

A recent meta-analysis of 20 randomized controlled trials of comparing bisphosphonates with either placebo or a different bisphosphonate as a comparator concluded that adding bisphosphonates to the treatment of MM reduces vertebral fractures and probably reduces pain. Whether zoledronate is superior to pamidronate and other bisphosphonates remains to be determined. ${ }^{197}$

The NCCN Guidelines for MM recommend bisphosphonates for all patients receiving myeloma therapy for symptomatic disease regardless of documented bone disease (category 1 ). In patients with smoldering or stage I MM, according to the NCCN Panel, bisphosphonates may be considered but preferably in a clinical trial. Skeletal survey annually or as clinically indicated is recommended for these patients. Bone densitometry or other metabolic studies should be reserved for clinical trials.

Low-dose radiation therapy (10-30 Gy) is used for the palliative treatment of uncontrolled pain, impending pathologic fracture, or impending spinal cord compression. ${ }^{49}$ Limited involved fields should be used to limit the effect of irradiation on stem cell harvest or its effect on potential future treatments; the radiation doses administered should not preclude stem cell collection in potential candidates for highdose therapy and hematopoietic SCT. Orthopedic consultation should be obtained for impending or actual fractures in weight-bearing bones, bony compression of the spinal cord, or vertebral column instability. Either vertebroplasty or kyphoplasty should be considered for symptomatic vertebral compression fractures.

Excess bone resorption from myeloma bone disease can lead to excessive release of calcium into the blood, contributing to hypercalcemia. Symptoms include polyuria and gastrointestinal disturbances, with progressive dehydration and decreases in glomerular filtration rate. Hypercalcemia should be treated with hydration and furosemide, bisphosphonates, steroids, and/or calcitonin. Among the bisphosphonates (zoledronic acid, pamidronate, and ibandronate), the NCCN Panel Members prefer zoledronic acid for treatment of hypercalcemia. ${ }^{198-200}$

Plasmapheresis should be used as adjunctive therapy for symptomatic hyperviscosity. ${ }^{201}$ Institutions differ in their use of plasmapheresis for adjunctive treatment of renal dysfunction.

Erythropoietin therapy should be considered for anemic patients, especially those with renal failure. Measuring endogenous erythropoietin levels may also be helpful in treatment planning ${ }^{202,203}$ (see NCCN Guidelines for Cancer and Treatment-Related Anemia, available at NCCN.org).

To prevent infection: 1) intravenous immunoglobulin therapy should be considered for recurrent, lifethreatening infections; 2) pneumococcal and influenza vaccine should also be considered; and 3) Pneumocystis carinii pneumonia, herpes, and antifungal prophylaxis is recommended if a high-dose regimen is used. Bortezomib treatment has been associated with an incidence of herpes zoster. ${ }^{72,73}$ Herpes prophylaxis is recommended in patients receiving bortezomib therapy. ${ }^{71}$ (See NCCN Guidelines for Prevention and Treatment of Cancer-Related Infections, available at NCCN.org).

Thrombosis is relatively common when thalidomide or lenalidomide is used with steroids, and is particularly frequent when treating newly diagnosed patients. Use of prophylactic anticoagulation agents (see NCCN Guidelines for Venous Thromboembolic Disease, available at NCCN.org) is recommended when immunomodulatory drugs are used in combination therapy during induction. $93,204,205$

Hydration should be maintained and NSAIDs should be avoided to decrease the chances of renal dysfunction. According to the NCCN Multiple Myeloma Panel Members, the use of plasmapheresis to improve renal function is a category $2 \mathrm{~B}$ recommendation. The use of intravenous contrast media and NSAIDs should also be avoided in patients with renal impairment.

\section{References}

1. . Siegel RL, Miller KD, Jemal A. Cancer statistics, 2015. CA Cancer J Clin 2015;65:5-29.

2. Brenner $\mathrm{H}$, Gondos $\mathrm{A}$, Pulte D. Recent major improvement in long-term survival of younger patients with multiple myeloma. Blood 2008;111:25212526.

3. Kumar SK, Rajkumar SV, Dispenzieri A, et al. Improved survival in multiple myeloma and the impact of novel therapies. Blood 2008;111:2516-2520.

4. Palumbo A, Anderson K. Multiple myeloma. N Engl J Med 2011;364:10461060.

5. Anderson KC. Oncogenomics to target myeloma in the bone marrow microenvironment. Clin Cancer Res 2011;17:1225-1233. 
6. Hideshima T, Anderson K. Molecular mechanisms of novel therapeutic approaches for multiple myeloma. Nat Rev Cancer 2002;2:927-937.

7. Dispenzieri A, Kyle R, Merlini G, et al. International Myeloma Working Group guidelines for serum-free light chain analysis in multiple myeloma and related disorders. Leukemia 2009;23:215-224.

8. Kuhnemund A, Liebisch P, Bauchmuller K, et al. 'Light-chain escapemultiple myeloma'-an escape phenomenon from plateau phase: report of the largest patient series using LC-monitoring. J Cancer Res Clin Oncol 2009; $135: 477-484$

9. Durie BG, Harousseau JL, Miguel JS, et al. International uniform response criteria for multiple myeloma. Leukemia 2006;20:1467-1473.

10. Kyle RA, Gertz MA, Witzig TE, et al. Review of 1027 patients with newly diagnosed multiple myeloma. Mayo Clin Proc 2003;78:21-33.

11. Shaughnessy J, Jacobson J, Sawyer J, et al. Continuous absence of metaphase-defined cytogenetic abnormalities, especially of chromosome 13 and hypodiploidy, ensures long-term survival in multiple myeloma treated with Total Therapy I: interpretation in the context of global gene expression. Blood 2003;101:3849-3856.

12. Xiong $\mathrm{W}, \mathrm{Wu} X$, Starnes $\mathrm{S}$, et al. An analysis of the clinical and biologic significance of TP53 loss and the identification of potential novel transcriptional targets of TP53 in multiple myeloma. Blood 2008;112:4235-4246.

13. Drach J, Ackermann J, Fritz E, et al. Presence of a p53 gene deletion in patients with multiple myeloma predicts for short survival after conventional-dose chemotherapy. Blood 1998;92:802-809.

14. Avet-Loiseau H, Attal M, Moreau P, et al. Genetic abnormalities and survival in multiple myeloma: the experience of the Intergroupe Francophone du Myelome. Blood 2007;109:3489-3495.

15. Gertz MA, Lacy MQ, Dispenzieri A, et al. Clinical implications of $\mathrm{t}(11 ; 14)$ $(\mathrm{q} 13 ; \mathrm{q} 32), \mathrm{t}(4 ; 14)(\mathrm{p} 16.3 ; \mathrm{q} 32)$, and $-17 \mathrm{p} 13$ in myeloma patients treated with high-dose therapy. Blood 2005;106:2837-2840.

16. Gutierrez NC, Castellanos MV, Martin ML, et al. Prognostic and biological implications of genetic abnormalities in multiple myeloma undergoing autologous stem cell transplantation: $\mathrm{t}(4 ; 14)$ is the most relevant adverse prognostic factor, whereas RB deletion as a unique abnormality is not associated with adverse prognosis. Leukemia 2007;21:143-150.

17. Ross FM, Avet-Loiseau H, Ameye G, et al. Report from the European Myeloma Network on interphase FISH in multiple myeloma and related disorders. Haematologica 2012;97:1272-1277.

18. Avet-Loiseau H, Malard F, Campion L, et al. Translocation $t(14 ; 16)$ and multiple myeloma: is it really an independent prognostic factor? Blood 2011;117:2009-2011.

19. Fonseca R, Blood E, Rue M, et al. Clinical and biologic implications of recurrent genomic aberrations in myeloma. Blood 2003;101:4569-4575.

20. Nair B, van Rhee F, Shaughnessy JD, Jr., et al. Superior results of Total Therapy 3 (2003-33) in gene expression profiling-defined low-risk multiple myeloma confirmed in subsequent trial 2006-66 with VRD maintenance. Blood 2010;115:4168-4173.

21. Dewald G, Therneau T, Larson D, et al. Relationship of patient survival and chromosome anomalies detected in metaphase and/or interphase cells at diagnosis of myeloma. Blood 2005;106:3553-3558

22. Fonseca R, Barlogie B, Bataille R, et al. Genetics and cytogenetics of multiple myeloma: a workshop report. Cancer Res 2004;64:1546-1558.

23. Hanamura I, Stewart JP, Huang Y, et al. Frequent gain of chromosome band 1q21 in plasma-cell dyscrasias detected by fluorescence in situ hybridization: incidence increases from MGUS to relapsed myeloma and is related to prognosis and disease progression following tandem stem-cell transplantation. Blood 2006;108:1724-1732

24. Carrasco DR, Tonon G, Huang Y, et al. High-resolution genomic profiles define distinct clinico-pathogenetic subgroups of multiple myeloma patients. Cancer Cell 2006;9:313-325.

25. Rosinol L, Carrio A, Blade J, et al. Comparative genomic hybridisation identifies two variants of smoldering multiple myeloma. Br J Haematol 2005;130:729-732

26. Dispenzieri A, Rajkumar SV, Gertz MA, et al. Treatment of newly diagnosed multiple myeloma based on Mayo Stratification of Myeloma and Risk-adapted Therapy (mSMART): consensus statement. Mayo Clin Proc 2007;82:323-341.

27. Kumar SK, Mikhael JR, Buadi FK, et al. Management of newly diagnosed symptomatic multiple myeloma: updated Mayo Stratification of Myeloma and Risk-Adapted Therapy (mSMART) consensus guidelines. Mayo Clin Proc 2009;84:1095-1110.
28. Moreau P, Attal M, Garban F, et al. Heterogeneity of $t(4 ; 14)$ in multiple myeloma. Long-term follow-up of 100 cases treated with tandem transplantation in IFM99 trials. Leukemia 2007;21:2020-2024.

29. Fonseca R, Bergsagel PL, Drach J, et al. International Myeloma Working Group molecular classification of multiple myeloma: spotlight review. Leukemia 2009;23:2210-2221

30. Zhou Y, Barlogie B, Shaughnessy JD, Jr. The molecular characterization and clinical management of multiple myeloma in the post-genome era Leukemia 2009;23:1941-1956.

31. Decaux O, Lode L, Magrangeas F, et al. Prediction of survival in multiple myeloma based on gene expression profiles reveals cell cycle and chromosomal instability signatures in high-risk patients and hyperdiploid signatures in low-risk patients: a study of the Intergroupe Francophone du Myelome. J Clin Oncol 2008;26:4798-4805.

32. Shaughnessy JD, Jr., Zhan F, Burington BE, et al. A validated gene expression model of high-risk multiple myeloma is defined by deregulated expression of genes mapping to chromosome 1. Blood 2007;109:22762284.

33. Kuiper R, Broyl A, de Knegt Y, et al. A gene expression signature for highrisk multiple myeloma. Leukemia 2012;26:2406-2413.

34. Moulopoulos LA, Dimopoulos MA, Weber D, et al. Magnetic resonance imaging in the staging of solitary plasmacytoma of bone. J Clin Oncol 1993;11:1311-1315.

35. Zamagni E, Cavo M. The role of imaging techniques in the management of multiple myeloma. Br J Haematol 2012;159:499-513.

36. Durie B, Waxman A, D'Agnolo A, Williams CM. Whole-body (18)F-FDG PET identifies high-risk myeloma. J Nucl Med 2002;43:1457-1463.

37. Schirrmeister $\mathrm{H}$, Bommer $\mathrm{M}$, Buck $\mathrm{AK}$, et al. Initial results in the assessment of multiple myeloma using 18F-FDG PET. Eur J Nucl Med Mol Imaging 2002;29:361-366.

38. Zamagni E, Patriarca F, Nanni C, et al. Prognostic relevance of 18-F FDG PET/CT in newly diagnosed multiple myeloma patients treated with up front autologous transplantation. Blood 2011;118:5989-5995.

39. Nanni C, Zamagni E, Celli M, et al. The value of 18F-FDG PET/CT after autologous stem cell transplantation (ASCT) in patients affected by multiple myeloma (MM): experience with 77 patients. Clin Nucl Med 2013;38:e74-79.

40. Greipp PR, Lust JA, O'Fallon WM, et al. Plasma cell labeling index and beta 2 -microglobulin predict survival independent of thymidine kinase and C-reactive protein in multiple myeloma. Blood 1993;81:3382-3387.

41. Rajkumar SV, Dimopoulos MA, Palumbo A, et al. International Myeloma Working Group updated criteria for the diagnosis of multiple myeloma. Lancet Oncol 2014;15:e538-548.

42. Greipp PR, San Miguel J, Durie BGM, et al. International staging system for multiple myeloma. J Clin Oncol 2005;23:3412-3420.

43. Blade J, Samson D, Reece D, et al. Criteria for evaluating disease response and progression in patients with multiple myeloma treated by high-dose therapy and haemopoietic stem cell transplantation. Myeloma Subcommittee of the EBMT. European Group for Blood and Marrow Transplant. Br J Haematol 1998;102:1115-1123.

44. Rajkumar SV. Multiple myeloma: 2011 update on diagnosis, risk stratification, and management. Am J Hematol 2011;86:57-65.

45. Palumbo A, Rajkumar SV, San Miguel JF, et al. International Myeloma Working Group consensus statement for the management, treatment, and supportive care of patients with myeloma not eligible for standard autologous stem-cell transplantation. J Clin Oncol 2014;32:587-600.

46. Knowling MA, Harwood AR, Bergsagel DE. Comparison of extramedullary plasmacytomas with solitary and multiple plasma cell tumors of bone. Clin Oncol 1983;1:255-262.

47. Dores GM, Landgren O, McGlynn KA, et al. Plasmacytoma of bone, extramedullary plasmacytoma, and multiple myeloma: incidence and survival in the United States, 1992-2004. Br J Haematol 2009;144:86-94.

48. Dimopoulos MA, Goldstein J, Fuller L, et al. Curability of solitary bone plasmacytoma. J Clin Oncol 1992;10:587-590.

49. Hu K, Yahalom J. Radiotherapy in the management of plasma cell tumors Oncology (Williston Park) 2000;14:101-108.

50. Creach KM, Foote RL, Neben-Wittich MA, Kyle RA. Radiotherapy for extramedullary plasmacytoma of the head and neck. Int J Radiat Oncol Biol Phys 2009;73:789-794.

51. Tournier-Rangeard L, Lapeyre M, Graff-Caillaud P, et al. Radiotherapy for solitary extramedullary plasmacytoma in the head-and-neck region: A dose greater than 45 Gy to the target volume improves the local control. Int Radiat Oncol Biol Phys 2006;64:1013-1017. 
52. Reed V, Shah J, Medeiros LJ, et al. Solitary plasmacytomas: outcome and prognostic factors after definitive radiation therapy. Cancer 2011;117:4468-4474

53. Frassica DA, Frassica FJ, Schray MF, et al. Solitary plasmacytoma of bone: Mayo Clinic experience. Int J Radiat Oncol Biol Phys 1989;16:43-48.

54. Ozsahin M, Tsang RW, Poortmans $\mathrm{P}$, et al. Outcomes and patterns of failure in solitary plasmacytoma: a multicenter Rare Cancer Network study of 258 patients. Int J Radiat Oncol Biol Phys 2006;64:210-217.

55. Knobel D, Zouhair A, Tsang RW, et al. Prognostic factors in solitary plasmacytoma of the bone: a multicenter Rare Cancer Network study. BMC Cancer 2006;6:118-118.

56. Sasaki R, Yasuda K, Abe E, et al. Multi-institutional analysis of solitary extramedullary plasmacytoma of the head and neck treated with curative radiotherapy. Int J Radiat Oncol Biol Phys 2012;82:626-634.

57. Gerry D, Lentsch EJ. Epidemiologic evidence of superior outcomes for extramedullary plasmacytoma of the head and neck. Otolaryngol Head Neck Surg 2013;148:974-981.

58. Kato T, Tsukamoto E, Nishioka T, et al. Early detection of bone marrow involvement in extramedullary plasmacytoma by whole-body F-18 FDG positron emission tomography. Clin Nucl Med 2000;25:870-873.

59. Nanni C, Rubello D, Zamagni E, et al. 18F-FDG PET/CT in myeloma with presumed solitary plasmocytoma of bone. In Vivo 2008;22:513-517.

60. The International Myeloma Working G. Criteria for the classification of monoclonal gammopathies, multiple myeloma and related disorders: a report of the International Myeloma Working Group. British Journal of Haematology 2003;121:749-757.

61. Cesana C, Klersy C, Barbarano L, et al. Prognostic factors for malignant transformation in monoclonal gammopathy of undetermined significance and smoldering multiple myeloma. J Clin Oncol 2002;20:1625-1634.

62. Mateos MV, Hernandez MT, Giraldo $P$, et al. Lenalidomide plus dexamethasone for high-risk smoldering multiple myeloma. N Engl J Med 2013;369:438-447.

63. Dimopoulos $\mathrm{M}$, Terpos $\mathrm{E}$, Comenzo RL, et al. International myeloma working group consensus statement and guidelines regarding the current role of imaging techniques in the diagnosis and monitoring of multiple Myeloma. Leukemia 2009.

64. Bredella MA, Steinbach L, Caputo G, et al. Value of FDG PET in the assessment of patients with multiple myeloma. AJR Am J Roentgenol 2005;184:1199-1204

65. Jadvar H, Conti PS. Diagnostic utility of FDG PET in multiple myeloma Skeletal Radiol 2002;31:690-694.

66. Orchard K, Barrington S, Buscombe J, et al. Fluoro-deoxyglucose positron emission tomography imaging for the detection of occult disease in multiple myeloma. Br J Haematol 2002;117:133-135.

67. Ocqueteau M, Orfao A, Almeida J, et al. Immunophenotypic characterization of plasma cells from monoclonal gammopathy of undetermined significance patients. Implications for the differential diagnosis between MGUS and multiple myeloma. Am J Pathol 1998;152:1655-1665.

68. Perez-Persona E, Vidriales MB, Mateo G, et al. New criteria to identify risk of progression in monoclonal gammopathy of uncertain significance and smoldering multiple myeloma based on multiparameter flow cytometry analysis of bone marrow plasma cells. Blood 2007;110:2586-2592.

69. Quach H, Ritchie D, Stewart AK, et al. Mechanism of action of immunomodulatory drugs (IMiDS) in multiple myeloma. Leukemia 2010;24:22-32

70. Avet-Loiseau H, Leleu X, Roussel M, et al. Bortezomib plus dexamethasone induction improves outcome of patients With $\mathrm{t}(4 ; 14)$ myeloma but not outcome of patients with del(17p). J Clin Oncol 2010.

71. Chanan-Khan A, Sonneveld P, Schuster M, et al. Analysis of herpes zoster events among bortezomib-treated patients in the phase III APEX study. J Clin Oncol 2008;26:4784-4790

72. Mateos M, Hernandez J, Hernandez M, et al. Bortezomib plus melphalan and prednisone in elderly untreated patients with multiple myeloma: results of a multicenter phase $1 / 2$ study. Blood 2006;108:2165-2172.

73. Richardson P, Sonneveld P, Schuster M, et al. Bortezomib or highdose dexamethasone for relapsed multiple myeloma. N Engl J Med 2005;352:2487-2498

74. Vickrey E, Allen S, Mehta J, Singhal S. Acyclovir to prevent reactivation of varicella zoster virus (herpes zoster) in multiple myeloma patients receiving bortezomib therapy. Cancer 2009;115:229-232.

75. Mateos MV. Management of treatment-related adverse events in patients with multiple myeloma. Cancer Treat Rev 2010;36 Suppl 2:S24-32.
76. Harousseau JL, Attal M, Avet-Loiseau H, et al. Bortezomib plus dexamethasone is superior to vincristine plus doxorubicin plus dexamethasone as induction treatment prior to autologous stem-cell transplantation in newly diagnosed multiple myeloma: results of the IFM 2005-01 phase III trial. J Clin Oncol 2010;28:4621-4629.

77. Richardson PG, Barlogie B, Berenson J, et al. A phase 2 study of bortezomib in relapsed, refractory myeloma. N Engl J Med 2003;348:2609-2617.

78. Moreau P, Avet-Loiseau H, Facon T, et al. Bortezomib plus dexamethasone versus reduced-dose bortezomib, thalidomide plus dexamethasone as induction treatment before autologous stem cell transplantation in newly diagnosed multiple myeloma. Blood 2011;118:5752-5758; quiz 5982.

79. Sonneveld P, Schmidt-Wolf IG, van der Holt B, et al. Bortezomib induction and maintenance treatment in patients with newly diagnosed multiple myeloma: results of the randomized phase III HOVON-65/ GMMG-HD4 trial. J Clin Oncol 2012;30:2946-2955.

80. Cavo M, Tacchetti P, Patriarca F, et al. Bortezomib with thalidomide plus dexamethasone compared with thalidomide plus dexamethasone as induction therapy before, and consolidation therapy after, double autologous stem-cell transplantation in newly diagnosed multiple myeloma: a randomised phase 3 study. Lancet 2010;376:2075-2085.

81. Kaufman JL, Nooka A, Vrana M, et al. Bortezomib, thalidomide, and dexamethasone as induction therapy for patients with symptomatic multiple myeloma: a retrospective study. Cancer 2010;116:3143-3151.

82. Rosinol L, Oriol A, Teruel AI, et al. Superiority of bortezomib, thalidomide, and dexamethasone (VTD) as induction pretransplantation therapy in multiple myeloma: a randomized phase 3 PETHEMA/GEM study. Blood 2012;120:1589-1596.

83. Reeder CB, Reece DE, Kukreti V, et al. Cyclophosphamide, bortezomib and dexamethasone induction for newly diagnosed multiple myeloma: high response rates in a phase II clinical trial. Leukemia 2009;23:1337-1341.

84. Einsele H, Liebisch $\mathrm{P}$, Langer $\mathrm{C}$, et al. Velcade, intravenous cyclophosphamide and dexamethasone (VCD) induction for previously untreated multiple myeloma (German DSMM XIa Trial) [abstract]. Blood 2009;114:Abstract 131.

85. Kumar S, Flinn I, Richardson PG, et al. Randomized, multicenter, phase 2 study (EVOLUTION) of combinations of bortezomib, dexamethasone, cyclophosphamide, and lenalidomide in previously untreated multiple myeloma. Blood 2012;119:4375-4382.

86. Reeder CB, Reece DE, Kukreti V, et al. Long-term survival with cyclophosphamide, bortezomib and dexamethasone induction therapy in patients with newly diagnosed multiple myeloma. Br J Haematol 2014;167:563-565

87. Reeder CB, Reece DE, Kukreti V, et al. Once- versus twice-weekly bortezomib induction therapy with CyBorD in newly diagnosed multiple myeloma. Blood 2010;115:3416-3417.

88. Zonder JA, Crowley J, Hussein MA, et al. Superiority of lenalidomide (Len) plus high-dose dexamethasone (HD) compared to HD alone as treatment of newly-diagnosed multiple myeloma (NDMM): Results of the randomized, double-blinded, placebo-controlled SWOG Trial S0232 [abstract]. Blood 2007;110:Abstract 77.

89. Rajkumar SV, Jacobus S, Callander N, et al. A randomized trial of lenalidomide plus high-dose dexamethasone (RD) versus lenalidomide plus low-dose dexamethasone (Rd) in newly diagnosed multiple myeloma (E4A03): a trial coordinated by the Eastern Cooperative Oncology Group [abstract]. Blood 2007;110:Abstract 74.

90. Rajkumar SV, Jacobus S, Callander NS, et al. Lenalidomide plus highdose dexamethasone versus lenalidomide plus low-dose dexamethasone as initial therapy for newly diagnosed multiple myeloma: an open-label randomised controlled trial. Lancet Oncol 2010;11:29-37.

91. Gay F, Hayman SR, Lacy MQ, et al. Lenalidomide plus dexamethasone versus thalidomide plus dexamethasone in newly diagnosed multiple myeloma: a comparative analysis of 411 patients. Blood 2010;115:13431350 .

92. Zangari M, Tricot G, Polavaram L, et al. Survival effect of venous thromboembolism in patients with multiple myeloma treated with lenalidomide and high-dose dexamethasone. J Clin Oncol 2010;28:132135.

93. Palumbo A, Rajkumar SV, Dimopoulos MA, et al. Prevention of thalidomide- and lenalidomide-associated thrombosis in myeloma. Leukemia 2008;22:414-423.

94. Kumar S, Dispenzieri A, Lacy MQ, et al. Impact of lenalidomide therapy on stem cell mobilization and engraftment post-peripheral blood stem cell transplantation in patients with newly diagnosed myeloma. Leukemia 2007;21:2035-2042. 
95. Paripati H, Stewart AK, Cabou S, et al. Compromised stem cell mobilization following induction therapy with lenalidomide in myeloma. Leukemia 2008;22:1282-1284.

96. Kumar S, Giralt S, Stadtmauer EA, et al. Mobilization in myeloma revisited: IMWG consensus perspectives on stem cell collection following initial therapy with thalidomide-, lenalidomide-, or bortezomib-containing regimens. Blood 2009;114:1729-1735.

97. Mark T, Stern J, Furst JR, et al. Stem cell mobilization with cyclophosphamide overcomes the suppressive effect of lenalidomide therapy on stem cell collection in multiple myeloma. Biol Blood Marrow Transplant 2008;14:795-798

98. Nademanee AP, DiPersio JF, Maziarz RT, et al. Plerixafor plus granulocyte colony-stimulating factor versus placebo plus granulocyte colonystimulating factor for mobilization of CD34(+) hematopoietic stem cells in patients with multiple myeloma and low peripheral blood CD34(+) cell count: results of a subset analysis of a randomized trial. Biol Blood Marrow Transplant 2012;18:1564-1572.

99. Duarte RF, Shaw BE, Marin P, et al. Plerixafor plus granulocyte CSF can mobilize hematopoietic stem cells from multiple myeloma and lymphoma patients failing previous mobilization attempts: EU compassionate use data. Bone Marrow Transplant 2010.

100. Richardson P, Weller E, Lonial S, et al. Lenalidomide, bortezomib, and dexamethasone combination therapy in patients with newly diagnosed multiple myeloma. Blood 2010;116:679-686

101. Roussel M, Lauwers-Cances V, Robillard N, et al. Front-line transplantation program with lenalidomide, bortezomib, and dexamethasone combination as induction and consolidation followed by lenalidomide maintenance in patients with multiple myeloma: a phase II study by the Intergroupe Francophone du Myelome. J Clin Oncol 2014;32:2712-2717.

102. Rajkumar S, Blood EA, Vesole D, et al. Phase III clinical trial of thalidomide plus dexamethasone compared with dexamethasone alone in newly diagnosed multiple myeloma: a clinical trial coordinated by the Eastern Cooperative Oncology Group. J Clin Oncol 2006;24:431-436.

103. Rifkin R, Gregory SA, Mohrbacher A, Hussein M. Pegylated liposomal doxorubicin, vincristine, and dexamethasone provide significant reduction in toxicity compared with doxorubicin, vincristine, and dexamethasone in patients with newly diagnosed multiple myeloma: a phase III multicenter randomized trial. Cancer 2006;106:848-858.

104. Arastu-Kapur S, Anderl JL, Kraus M, et al. Nonproteasomal targets of the proteasome inhibitors bortezomib and carfilzomib: a link to clinical adverse events. Clin Cancer Res 2011;17:2734-2743.

105. Kirk CJ, Jiang J, Muchamuel T, et al. The selective proteasome inhibitor carfilzomib is well tolerated in experimental animals with dose intensive administration [abstract]. Blood 2008;112:Abstract 2765.

106. Siegel DS, Martin T, Wang M, et al. A phase 2 study of single-agent carfilzomib (PX-171-003-A1) in patients with relapsed and refractory multiple myeloma. Blood 2012;120:2817-2825.

107. Vij R, Wang M, Kaufman JL, et al. An open-label, single-arm, phase 2 (PX171-004) study of single-agent carfilzomib in bortezomib-naive patients with relapsed and/or refractory multiple myeloma. Blood 2012;119:56615670 .

108. Vij R, Wang M, Orlowski R, et al. Initial results of PX-171-003, an open-label, single-arm, phase II study of carfilzomib (CFZ) in patients with relapsed and refractory multiple myeloma (MM) [abstract]. Blood 2008;112:Abstract 865

109. Jakubowiak AJ, Dytfeld D, Griffith KA, et al. A phase $1 / 2$ study of carfilzomib in combination with lenalidomide and low-dose dexamethasone as a frontline treatment for multiple myeloma. Blood 2012;120:1801-1809.

110. Dytfeld D, Jasielec J, Griffith KA, et al. Carfilzomib, lenalidomide, and low-dose dexamethasone in elderly patients with newly diagnosed multiple myeloma. Haematologica 2014;99:e162-164.

111. Korde N, Zingone A, Kwok M, et al. Phase II clinical and correlative study of carfilzomib, lenalidomide, and dexamethasone (CRd) in newly diagnosed Multiple Myeloma (MM) patients [abstract]. Blood 2012;120:Abstract 732.

112. Korde N, Zingone A, Kwok M, et al. Phase II Clinical and Correlative Study Of Carfilzomib, Lenalidomide, and Dexamethasone Followed By Lenalidomide Extended Dosing (CRD-R) Induces High Rates Of MRD Negativity In Newly Diagnosed Multiple Myeloma (MM) Patients [Abstract]. Vol. 122; 2013.

113. Gregory WM, Richards MA, Malpas JS. Combination chemotherapy versus melphalan and prednisolone in the treatment of multiple myeloma: an overview of published trials. J Clin Oncol 1992;10:334-342.

114. Palumbo A, Bringhen $S$, Caravita $T$, et al. Oral melphalan and prednisone chemotherapy plus thalidomide compared with melphalan and prednisone alone in elderly patients with multiple myeloma: randomised controlled trial. Lancet 2006;367:825-831.

115. Palumbo A, Bringhen S, Liberati AM, et al. Oral melphalan, prednisone, and thalidomide in elderly patients with multiple myeloma: updated result of a randomized controlled trial. Blood 2008;112:3107-3114.

116. Facon T, Mary JY, Hulin C, et al. Melphalan and prednisone plus thalidomide versus melphalan and prednisone alone or reduced-intensity autologous stem cell transplantation in elderly patients with multiple myeloma (IFM 99-06): a randomised trial. Lancet 2007;370:1209-1218.

117. Hulin C, Facon T, Rodon P, et al. Efficacy of melphalan and prednisone plus thalidomide in patients older than 75 years with newly diagnosed multiple myeloma: IFM 01/01 trial. J Clin Oncol 2009;27:3664-3670.

118. Wijermans P, Schaafsma M, Termorshuizen F, et al. Phase III study of the value of thalidomide added to melphalan plus prednisone in elderly patients with newly diagnosed multiple myeloma: the HOVON 49 Study. J Clin Oncol 2010;28:3160-3166.

119. Kapoor P, Rajkumar SV, Dispenzieri A, et al. Melphalan and prednisone versus melphalan, prednisone and thalidomide for elderly and/or transplant ineligible patients with multiple myeloma: a meta-analysis. Leukemia 2011;25:689-696.

120. Palumbo A, Falco P, Corradini P, et al. Melphalan, prednisone, and lenalidomide treatment for newly diagnosed myeloma: a report from the GIMEMA--Italian Multiple Myeloma Network. J Clin Oncol 2007;25:4459-4465.

121. Roy V, Stewart A, Bergsagel $P$, et al. Phase II study of melphalan, prednisone and lenalidomide combination for newly diagnosed multiple myeloma patients who are not candidates for stem cell transplantation [abstract]. Blood 2008;112:Abstract 2769.

122. Palumbo A, Hajek $R$, Delforge $M$, et al. Continuous lenalidomide treatment for newly diagnosed multiple myeloma. $N$ Engl J Med 2012;366:1759-1769.

123. Stewart A, Jacobus S, Fonseca F, et al. E1A06: A phase III trial comparing melphalan, prednisone, and thalidomide (MPT) versus melphalan, prednisone, and lenalidomide (MPR) in newly diagnosed multiple myeloma (MM) [Abstract]. J Clin Oncol 2014;32: 5s_suppl:Abstract 8511.

124. San Miguel JF, Schlag R, Khuageva NK, et al. Bortezomib plus melphalan and prednisone for initial treatment of multiple myeloma. N Engl J Med 2008;359:906-917.

125. San Miguel JF, Schlag R, Khuageva NK, et al. Persistent overall survival benefit and no increased risk of second malignancies with bortezomibmelphalan-prednisone versus melphalan-prednisone in patients with previously untreated multiple myeloma. J Clin Oncol 2013;31:448-455.

126. Yeh Y, Chambers J, Gaugris S, Jansen J. Indirect comparison of the efficacy of melphalan-prednisone-bortezomib relative to melphalan-prednisonethalidomide and melphalan-prednisone for the first line treatment of Multiple myeloma [abstract]. Blood 2008;112:Abstract 2367.

127. Harousseau JL, Palumbo A, Richardson PG, et al. Superior outcomes associated with complete response in newly diagnosed multiple myeloma patients treated with nonintensive therapy: analysis of the phase 3 VISTA study of bortezomib plus melphalan-prednisone versus melphalanprednisone. Blood 2010;116:3743-3750.

128. Rajkumar SV, Jacobus S, Callander N, et al. A randomized phase III trial of lenalidomide pus high-dose dexamethasone versus lenalidomide plus low-dose dexamethasone in newly diagnosed multiple myeloma (E4A03): a trial coordinated by the eastern Cooperative Oncology Group [abstract] Blood 2006;108:Abstract 799.

129. Benboubker L, Dimopoulos MA, Dispenzieri A, et al. Lenalidomide and dexamethasone in transplant-ineligible patients with myeloma. New England Journal of Medicine 2014;371:906-917.

130. Attal M, Lauwers-Cances V, Marit G, et al. Lenalidomide maintenance after stem-cell transplantation for multiple myeloma. N Engl J Med 2012;366:1782-1791.

131. McCarthy PL, Owzar K, Hofmeister CC, et al. Lenalidomide after stem-cell transplantation for multiple myeloma. N Engl J Med 2012;366:1770-1781.

132. Usmani S, Sexton R, Hoering A, et al. Second malignancies in total therapy 3 trials for newly diagnosed multiple myeloma: Influence of lenalidomide versus thalidomide in maintenance phases [abstract]. Blood 2011;118:Abstract 823 .

133. Palumbo A, Bringhen S, Kumar SK, et al. Second primary malignancies with lenalidomide therapy for newly diagnosed myeloma: a meta-analysis of individual patient data. Lancet Oncol 2014;15:333-342.

134. Niesvizky R, Flinn IW, Rifkin R, et al. Efficacy and safety of three bortezomib-based combinations in elderly, newly diagnosed multiple myeloma patients: Results from all randomized patients in the community based, phase 3b UPFRONT study [abstract]. Blood 2011;118:Abstract 478 . 
135. Jimenez Zepeda VH, Duggan P, Neri PE, Bahlis NJ. Cyclophosphamide, bortezomib and dexamethasone (CyBORD) is a feasible and active regimen for non-transplant Eligible Multiple Myeloma Patients. Vol. 124; 2014.

136. Badros A, Barlogie B, Morris C, et al. High response rate in refractory and poor-risk multiple myeloma after allotransplantation using a nonmyeloablative conditioning regimen and donor lymphocyte infusions. Blood 2001;97:2574-2579.

137. Kroger N, Sayer HG, Schwerdtfeger R, et al. Unrelated stem cell transplantation in multiple myeloma after a reduced-intensity conditioning with pretransplantation antithymocyte globulin is highly effective with low transplantation-related mortality. Blood 2002;100:3919-3924.

138. Moreau P, Facon T, Attal M, et al. Comparison of $200 \mathrm{mg} / \mathrm{m}(2)$ melphalan and 8 Gy total body irradiation plus $140 \mathrm{mg} / \mathrm{m}(2)$ melphalan as conditioning regimens for peripheral blood stem cell transplantation in patients with newly diagnosed multiple myeloma: final analysis of the Intergroupe Francophone du Myelome 9502 randomized trial. Blood 2002;99:731-735.

139. Somlo G, Spielberger R, Frankel P, et al. Total marrow irradiation: a new ablative regimen as part of tandem autologous stem cell transplantation for patients with multiple myeloma. Clin Cancer Res 2011;17:174-182.

140. Attal M, Harousseau JL, Stoppa AM, et al. A prospective, randomized trial of autologous bone marrow transplantation and chemotherapy in multiple myeloma. Intergroupe Francais du Myelome. N Engl J Med 1996;335:9197.

141. Child J, Morgan G, Davies F, et al. High-dose chemotherapy with hematopoietic stem-cell rescue for multiple myeloma. N Engl J Med 2003;348:1875-1883

142. Barlogie B, Kyle R, Anderson $K$, et al. Standard chemotherapy compared with high-dose chemoradiotherapy for multiple myeloma: final results of phase III US Intergroup Trial S9321. J Clin Oncol 2006;24:929-936.

143. Fermand J, Katsahian S, Divine M, et al. High-dose therapy and autologous blood stem-cell transplantation compared with conventional treatment in myeloma patients aged 55 to 65 years: long-term results of a randomized control trial from the Group Myelome-Autogreffe. J Clin Oncol 2005;23:9227-9233

144. Cavo M, Tacchetti P, Patriarca F, et al. Superior complete response rate and progression-free survival after autologous transplantation with upfront velcade-thalidomide-dexamethasone compared with thalidomidedexamethasone in newly diagnosed multiple myeloma [abstract] Blood 2008;112:Abstract 158.

145. Fermand JP, Ravaud P, Chevret S, et al. High-dose therapy and autologous peripheral blood stem cell transplantation in multiple myeloma: up-front or rescue treatment? Results of a multicenter sequential randomized clinical trial. Blood 1998;92:3131-3136.

146. Palumbo A, Cavallo F, Gay F, et al. Autologous Transplantation and Maintenance Therapy in Multiple Myeloma. New England Journal of Medicine 2014;371:895-905.

147. Palumbo A, Cavallo F, Gay F, et al. Autologous transplantation and maintenance therapy in multiple myeloma. N Engl J Med 2014;371:895905.

148. Cavo M, Tacchetti P, Patriarca F, et al. A phase III study of double autotransplantation incorporating bortezomib-thalidomidedexamethasone (VTD) or thalidomide-dexamethasone (TD) for multiple myeloma: superior clinical outcomes with VTD compared to TD [abstract]. Blood 2009;114:Abstract 351.

149. Hahn T, Wingard J, Anderson $K$, et al. The role of cytotoxic therapy with hematopoietic stem cell transplantation in the therapy of multiple myeloma: an evidence-based review. Biol Blood Marrow Transplant 2003;9:4-37.

150. Kumar S, Lacy MQ, Dispenzieri A, et al. High-dose therapy and autologous stem cell transplantation for multiple myeloma poorly responsive to initial therapy. Bone Marrow Transplant 2004;34:161-167.

151. Attal M, Harousseau J, Facon T, et al. Single versus double autologous stemcell transplantation for multiple myeloma. N Engl J Med 2003;349:24952502.

152. Stadtmauer EA. Multiple myeloma, 2004--one or two transplants? N Engl J Med 2003;349:2551-2553.

153. Cavo M, Tosi P, Zamagni E, et al. Prospective, randomized study of single compared with double autologous stem-cell transplantation for multiple myeloma: Bologna 96 clinical study. J Clin Oncol 2007;25:2434-2441.

154. Sonneveld $P$, van der Holt $B$, Segeren $C$, et al. Intensive versus double intensive therapy in untreated multiple myeloma: Updated analysis of the randomized phase III study HOVON $24 \mathrm{MM}$ [abstract]. Blood 2004;104:Abstract 948.
155. Goldschmidt H. Single vs double high-dose therapy in multiple myeloma: second analysis of the GMMG-HD2 trial Haematologica 2005;90(s1):Abstract 38

156. Barlogie B, Attal M, Crowley J, et al. Long-term follow-up of autotransplantation trials for multiple myeloma: update of protocols conducted by the intergroupe francophone du myelome, southwest oncology group, and university of arkansas for medical sciences. J Clin Oncol 2010;28:1209-1214.

157. Kyle RA. High-dose therapy in multiple myeloma and primary amyloidosis: an overview. Semin Oncol 1999;26:74-83.

158. Kumar A, Loughran $T$, Alsina M, et al. Management of multiple myeloma: a systematic review and critical appraisal of published studies. Lancet Oncol 2003;4:293-304.

159. Bruno B, Rotta M, Patriarca F, et al. A comparison of allografting with autografting for newly diagnosed myeloma. N Engl J Med 2007;356:1110 1120 .

160. Rosinol L, Perez-Simon JA, Sureda A, et al. A prospective PETHEMA study of tandem autologous transplantation versus autograft followed by reduced-intensity conditioning allogeneic transplantation in newly diagnosed multiple myeloma. Blood 2008;112:3591-3593.

161. Garban F, Attal M, Michallet M, et al. Prospective comparison of autologous stem cell transplantation followed by dose-reduced allograft (IFM99-03 trial) with tandem autologous stem cell transplantation (IFM99-04 trial) in high-risk de novo multiple myeloma. Blood 2006;107:3474-3480.

162. Krishnan A, Pasquini MC, Logan B, et al. Autologous haemopoietic stemcell transplantation followed by allogeneic or autologous haemopoietic stem-cell transplantation in patients with multiple myeloma (BMT CTN 0102): a phase 3 biological assignment trial. Lancet Oncol 2011;12:11951203.

163. Bjorkstrand B, Iacobelli S, Hegenbart U, et al. Tandem autologous/ reduced-intensity conditioning allogeneic stem-cell transplantation versus autologous transplantation in myeloma: long-term follow-up. J Clin Oncol 2011;29:3016-3022.

164. Zeiser R, Bertz H, Spyridonidis A, et al. Donor lymphocyte infusions for multiple myeloma: clinical results and novel perspectives. Bone Marrow Transplant 2004;34:923-928.

165. van de Donk NW, Kroger N, Hegenbart U, et al. Prognostic factors for donor lymphocyte infusions following non-myeloablative allogeneic stem cell transplantation in multiple myeloma. Bone Marrow Transplant 2006;37:1135-1141.

166. Lokhorst HM, Wu K, Verdonck LF, et al. The occurrence of graft-versushost disease is the major predictive factor for response to donor lymphocyte infusions in multiple myeloma. Blood 2004;103:4362-4364.

167. Lokhorst HM, Schattenberg A, Cornelissen JJ, et al. Donor lymphocyte infusions for relapsed multiple myeloma after allogeneic stem-cell transplantation: predictive factors for response and long-term outcome. J Clin Oncol 2000;18:3031-3037.

168. Lokhorst HM, Schattenberg A, Cornelissen JJ, et al. Donor leukocyte infusions are effective in relapsed multiple myeloma after allogeneic bone marrow transplantation. Blood 1997;90:4206-4211.

169. Salama M, Nevill T, Marcellus D, et al. Donor leukocyte infusions for multiple myeloma. Bone Marrow Transplant 2000;26:1179-1184.

170. Tricot G, Vesole DH, Jagannath $S$, et al. Graft-versus-myeloma effect: proof of principle. Blood 1996;87:1196-1198.

171. Ayuk F, Shimoni A, Nagler A, et al. Efficacy and toxicity of low-dose escalating donor lymphocyte infusion given after reduced intensity conditioning allograft for multiple myeloma. Leukemia 2004;18:659-662.

172. Brinker BT, Waller EK, Leong $\mathrm{T}$, et al. Maintenance therapy with thalidomide improves overall survival after autologous hematopoietic progenitor cell transplantation for multiple myeloma. Cancer 2006;106:2171-2180.

173. Attal M, Harousseau J, Leyvraz S, et al. Maintenance therapy with thalidomide improves survival in patients with multiple myeloma. Blood 2006;108:3289-3294.

174. Morgan GJ, Jackson GH, Davies FE, et al. Maintenance thalidomide may improve progression free but not overall survival: Results from the Myeloma IX maintenance randomization [Abstract]. Blood 2008;112:Abstract 565.

175. Barlogie B, Tricot G, Anaissie E, et al. Thalidomide and hematopoietic-cell transplantation for multiple myeloma. N Engl J Med 2006;354:1021-1030.

176. Spencer A, Prince $M$, Roberts A, et al. First analysis of the Australasian Leukaemia and Lymphoma Group (ALLG) Trial of thalidomide and alternate day prednisolone following autologous stem cell transplantation (ASCT) for patients with multiple myeloma (ALLG MM6) [abstract]. Blood 2006;108:Abstract 58. 
177. Stewart AK, Trudel S, Bahlis NJ, et al. A randomized phase 3 trial of thalidomide and prednisone as maintenance therapy after ASCT in patients with MM with a quality-of-life assessment: the National Cancer Institute of Canada Clinicals Trials Group Myeloma 10 Trial. Blood 2013;121:1517-1523.

178. Kneppers E, van der Holt B, Kersten MJ, et al. Lenalidomide maintenance following non-myeloablative allogeneic stem cell transplantation in multiple myeloma is not feasible: results of the HOVON 76 trial. Blood 2011.

179. Alsina M, Becker PS, Zhong X, et al. Lenalidomide maintenance for highrisk multiple myeloma after allogeneic hematopoietic cell transplantation. Biol Blood Marrow Transplant 2014;20:1183-1189.

180. Usmani SZ, Sexton R, Hoering A, et al. Second malignancies in total therapy 2 and 3 for newly diagnosed multiple myeloma: influence of thalidomide and lenalidomide during maintenance. Blood 2012;120:15971600 .

181. Singh PP, Kumar SK, LaPlant BR, et al. Lenalidomide maintenance therapy in multiple myeloma: a meta-analysis of randomized trials [asbtract]. American Society of Hematology Annual Meeting. 2013; Abstract 407.

182. Mellqvist UH, Gimsing P, Hjertner $\mathrm{O}$, et al. Bortezomib consolidation after autologous stem cell transplantation in multiple myeloma: a Nordic Myeloma Study Group randomized phase 3 trial. Blood 2013;121:46474654 .

183. Niesvizky R, Flinn IW, Rifkin RM, et al. Phase 3b UPFRONT study: safety and efficacy of weekly bortezomib maintenance therapy after bortezomibbased induction regimens in elderly, newly diagnosed multiple myeloma patients [abstract]. Blood 2010;116:Abstract 619.

184. Browman GP, Bergsagel D, Sicheri D, et al. Randomized trial of interferon maintenance in multiple myeloma: a study of the National Cancer Institute of Canada Clinical Trials Group. J Clin Oncol 1995;13:2354-2360.

185. Fritz E, Ludwig $H$. Interferon-alpha treatment in multiple myeloma: meta-analysis of 30 randomised trials among 3948 patients. Ann Oncol 2000;11:1427-1436.

186. Shustik C, Belch A, Robinson S, et al. A randomised comparison of melphalan with prednisone or dexamethasone as induction therapy and dexamethasone or observation as maintenance therapy in multiple myeloma: NCIC CTG MY.7. Br J Haematol 2007;136:203-211.

187. Rosinnol L, Oriol A, Teruel AI, et al. Maintenance therapy after stemcell transplantation for multiple myeloma with bortezomib/thalidomide Vs. thalidomide Vs. alfa2b-interferon: Final results of a phase III pethema/ GEM randomized trial [abstract]. Blood 2012;120:Abstract 334.

188. Mateos MV, Oriol A, Martinez-Lopez J, et al. Maintenance therapy with bortezomib plus thalidomide or bortezomib plus prednisone in elderly multiple myeloma patients included in the GEM2005MAS65 trial. Blood 2012;120:2581-2588.

189. Berenson JR, Lichtenstein A, Porter L, et al. Long-term pamidronate treatment of advanced multiple myeloma patients reduces skeletal events. Myeloma Aredia Study Group. J Clin Oncol 1998;16:593-602.

190. Berenson JR, Lichtenstein A, Porter L, et al. Efficacy of pamidronate in reducing skeletal events in patients with advanced multiple myeloma. Myeloma Aredia Study Group. N Engl J Med 1996;334:488-493.

191. Major P, Lortholary A, Hon J, et al. Zoledronic acid is superior to pamidronate in the treatment of hypercalcemia of malignancy: a pooled analysis of two randomized, controlled clinical trials. J Clin Oncol 2001;19:558-567.

192. Zervas $K$, Verrou E, Teleioudis $Z$, et al. Incidence, risk factors and management of osteonecrosis of the jaw in patients with multiple myeloma: a single-centre experience in 303 patients. Br J Haematol 2006;134:620 623.

193. Morgan GJ, Davies FE, Gregory WM, et al. First-line treatment with zoledronic acid as compared with clodronic acid in multiple myeloma (MRC Myeloma IX): a randomised controlled trial. Lancet 2010;376:1989-1999.

194. Boyd K, Morgan G, Davies F, et al. Does zoledronic acid (ZOL) reduce skeletal-related events (SREs) and improve progression-free survival (PFS) in patients (Pts) with multiple myeloma (MM) with or without bone disease? MRC myeloma IX study results [abstract]. J Clin Oncol 2011;29:Abstract 8010.

195. Morgan GJ, Davies F, Gregory W, et al. Defining the biological subgroup of multiple myeloma patients which benefits maximally from the overall survival (OS) benefit associated with treatment with zoledronic acid (ZOL) [abstract]. J Clin Oncol 2011;29:Abstract 8083.

196. Morgan GJ, Davies FE, Gregory WM, et al. Long-term follow-up of MRC Myeloma IX trial: Survival outcomes with bisphosphonate and thalidomide treatment. Clin Cancer Res 2013;19:6030-6038.

197. Mhaskar R, Redzepovic J, Wheatley K, et al. Bisphosphonates in multiple myeloma: a network meta-analysis. Cochrane Database Syst Rev 2012;5:CD003188

198. Major PP, Coleman RE. Zoledronic acid in the treatment of hypercalcemia of malignancy: results of the international clinical development program. Semin Oncol 2001;28:17-24.

199. Major P, Lortholary A, Hon J, et al. Zoledronic acid is superior to pamidronate in the treatment of hypercalcemia of malignancy: a pooled analysis of two randomized, controlled clinical trials. J Clin Oncol 2001;19:558-567.

200. Pecherstorfer M, Steinhauer EU, Rizzoli R, et al. Efficacy and safety of ibandronate in the treatment of hypercalcemia of malignancy: a randomized multicentric comparison to pamidronate. Support Care Cancer 2003;11:539-547.

201. Lindsley $H$, Teller $D$, Noonan $B$, et al. Hyperviscosity syndrome in multiple myeloma. A reversible, concentration-dependent aggregation of the myeloma protein. Am J Med 1973;54:682-688.

202. Ludwig H, Fritz E, Kotzmann H, et al. Erythropoietin treatment of anemia associated with multiple myeloma. N Engl J Med 1990;322:1693-1699.

203. Osterborg A, Boogaerts MA, Cimino R, et al. Recombinant human erythropoietin in transfusion-dependent anemic patients with multiple myeloma and non-Hodgkin's lymphoma--a randomized multicenter study. The European Study Group of Erythropoietin (Epoetin Beta) Treatment in Multiple Myeloma and Non-Hodgkin's Lymphoma. Blood 1996;87:26752682.

204. Ikhlaque N, Seshadri V, Kathula S, Baumann M. Efficacy of prophylactic warfarin for prevention of thalidomide-related deep venous thrombosis. Am J Hematol 2006;81:420-422.

205. Baz R, Li L, Kottke-Marchant K, et al. The role of aspirin in the prevention of thrombotic complications of thalidomide and anthracycline-based chemotherapy for multiple myeloma. Mayo Clin Proc 2005;80: 1568-1574. 


\begin{tabular}{|c|c|c|c|c|}
\hline Panel Member & $\begin{array}{l}\text { Clinical Research Support/ } \\
\text { Data Safety Monitoring Board }\end{array}$ & $\begin{array}{l}\text { Scientific Advisory Boards, } \\
\text { Consultant, or Expert Witness }\end{array}$ & $\begin{array}{l}\text { Promotional Advisory Boards, } \\
\text { Consultant, or Speakers Bureau }\end{array}$ & Date Completed \\
\hline Melissa Alsina, MD & None & Onyx Pharmaceuticals, Inc. & Onyx Pharmaceuticals, Inc. & $1 / 21 / 15$ \\
\hline Kenneth C. Anderson, MD ${ }^{\mathrm{a}}$ & None & $\begin{array}{l}\text { Bristol-Myers Squibb Company; } \\
\text { Celgene Corporation; Gilead Sciences; } \\
\text { Millennium Pharmaceuticals, Inc.; } \\
\text { and sanofi-aventis U.S. }\end{array}$ & None & $1 / 23 / 15$ \\
\hline Djordje Atanackovic, MD & $\begin{array}{l}\text { Array Biopharma; and sanofi-aventis } \\
\text { U.S. }\end{array}$ & Onyx Pharmaceuticals, Inc. & $\begin{array}{l}\text { Celgene Corporation; Millennium } \\
\text { Pharmaceuticals, Inc.; and Onyx } \\
\text { Pharmaceuticals, Inc. }\end{array}$ & $1 / 16 / 15$ \\
\hline J. Sybil Biermann, MD & None & None & None & $3 / 25 / 15$ \\
\hline Jason C. Chandler, MD & None & $\begin{array}{l}\text { Alexion Pharmaceuticals, Inc.; Bristol- } \\
\text { Myers Squibb Company; and Onyx } \\
\text { Pharmaceuticals, Inc. }\end{array}$ & None & $1 / 22 / 15$ \\
\hline Caitlin Costello, MD & None & None & None & $4 / 06 / 15$ \\
\hline Benjamin Djulbegovic, MD, PhD & None & None & None & $1 / 20 / 15$ \\
\hline Henry C. Fung, MD, FACP, FRCP & None & None & $\begin{array}{l}\text { Genzyme Corporation; and Seattle } \\
\text { Genetics }\end{array}$ & $8 / 15 / 15$ \\
\hline Cristina Gasparetto, MD & Celgene Corporation & $\begin{array}{l}\text { Celgene Corporation; and } \\
\text { Millennium Pharmaceuticals, Inc. }\end{array}$ & None & $1 / 27 / 15$ \\
\hline Kelly Godby, MD & None & None & None & $7 / 23 / 15$ \\
\hline Craig Hofmeister, MD, MPH & None & None & None & $3 / 18 / 15$ \\
\hline Leona Holmberg, MD, PhD & $\begin{array}{l}\text { Merck \& Co., Inc.; Millennium } \\
\text { Pharmaceuticals, Inc.; sanofi-aventis } \\
\text { U.S.; and Seattle Genetics }\end{array}$ & $\begin{array}{l}\text { sanofi-aventis U.S.; and Seattle } \\
\text { Genetics }\end{array}$ & None & $8 / 26 / 15$ \\
\hline Sarah Holstein, MD, PhD & None & $\begin{array}{l}\text { Celgene Corporation; and } \\
\text { Millennium Pharmaceuticals, Inc. }\end{array}$ & None & $6 / 16 / 15$ \\
\hline Carol Ann Huff, MD & Medlmmune Inc.; and Pharmacyclics & $\begin{array}{l}\text { Celgene Corporation; Millennium } \\
\text { Pharmaceuticals, Inc.; and Novartis } \\
\text { Pharmaceuticals Corporation }\end{array}$ & None & $5 / 08 / 15$ \\
\hline Adetola Kassim, MD, MS & None & None & None & $3 / 18 / 15$ \\
\hline Amrita Y. Krishnan, MDa & $\begin{array}{l}\text { Jannsen Pharmaceutica Products, LP; } \\
\text { and the University of lowa }\end{array}$ & None & $\begin{array}{l}\text { Celgene Corporation; Millennium } \\
\text { Pharmaceuticals, Inc.; and Onyx } \\
\text { Pharmaceuticals, Inc. }\end{array}$ & $01 / 24 / 15$ \\
\hline Shaji K. Kumar, MD & $\begin{array}{l}\text { Celgene Corporation; Millennium } \\
\text { Pharmaceuticals, Inc.; Novartis } \\
\text { Pharmaceuticals Corporation; and } \\
\text { sanofi-aventis U.S. }\end{array}$ & $\begin{array}{l}\text { Celgene Corporation; Millennium } \\
\text { Pharmaceuticals, Inc.; Onyx } \\
\text { Pharmaceuticals, Inc.; sanofi-aventis } \\
\text { U.S.; and Skyline Diagnostics }\end{array}$ & None & $3 / 12 / 15$ \\
\hline Michaela Liedtke, MD & None & $\begin{array}{l}\text { Amgen Inc.; and Takeda } \\
\text { Pharmaceuticals North America, Inc. }\end{array}$ & None & $4 / 04 / 15$ \\
\hline Matthew Lunning, DO & None & $\begin{array}{l}\text { Celgene Corporation; Genentech, } \\
\text { Inc.; Gilead; Juno; Spectrum; and TG } \\
\text { therapeutics }\end{array}$ & None & $2 / 04 / 15$ \\
\hline Noopur Raje, MD & $\begin{array}{l}\text { Acetylon; Amgen Inc.; and Eli Lilly and } \\
\text { Company }\end{array}$ & $\begin{array}{l}\text { Celgene Corporation; Millennium } \\
\text { Pharmaceuticals, Inc.; and Onyx } \\
\text { Pharmaceuticals, Inc. }\end{array}$ & Amgen; and Celegene & $1 / 21 / 15$ \\
\hline Seema Singhal, MD & $\begin{array}{l}\text { Abbott Laboratories; Array; Jannsen } \\
\text { Pharmaceutica Products, LP; and Onyx } \\
\text { Pharmaceuticals, Inc. }\end{array}$ & $\begin{array}{l}\text { Celgene Corporation; and } \\
\text { Millennium Pharmaceuticals, Inc. }\end{array}$ & $\begin{array}{l}\text { Celgene Corporation; and Millennium } \\
\text { Pharmaceuticals, Inc. }\end{array}$ & $1 / 23 / 15$ \\
\hline Clayton Smith, MD & NA & NA & NA & Pending \\
\hline George Somlo, MD & National Cancer Institute & $\begin{array}{l}\text { Celgene Corporation; Millennium } \\
\text { Pharmaceuticals, Inc.; and Pfizer Inc. }\end{array}$ & $\begin{array}{l}\text { Celgene Corporation; Millennium } \\
\text { Pharmaceuticals, Inc.; Novartis } \\
\text { Pharmaceuticals Corporation; Pfizer Inc.; } \\
\text { and sanofi-aventis U.S. }\end{array}$ & $1 / 21 / 15$ \\
\hline Keith Stockerl-Goldstein, MD & None & None & $\begin{array}{l}\text { Celgene Corporation; Millennium } \\
\text { Pharmaceuticals, Inc.; and Onyx } \\
\text { Pharmaceuticals, Inc. }\end{array}$ & $1 / 21 / 15$ \\
\hline Steven P. Treon, MD, PhD & $\begin{array}{l}\text { Jannsen Pharmaceutica Products, } \\
\text { LP; Onyx Pharmaceuticals, Inc.; and } \\
\text { Pharmacyclics }\end{array}$ & None & $\begin{array}{l}\text { Jannsen Pharmaceutica Products, LP; Onyx } \\
\text { Pharmaceuticals, Inc.; and Pharmacyclics }\end{array}$ & $4 / 07 / 15$ \\
\hline Donna Weber, MD & $\begin{array}{l}\text { Merck \& Co., Inc.; and Novartis } \\
\text { Pharmaceuticals Corporation }\end{array}$ & None & None & $9 / 26 / 13$ \\
\hline Joachim Yahalom, MD & None & None & None & $9 / 29 / 15$ \\
\hline
\end{tabular}

The following have disclosed that they have an Employment/Governing Board, Patent, Equity, or Royalty conflict: Kenneth Anderson, MD: Actelion Pharmaceuticals Ltd. and OncoPep, Inc.

Amrita Krishnan, MD: Celgene Corporation, and Pharmacyclics, Inc.

The NCCN Guidelines staff have no conflicts to disclose. 